\title{
Endogenous formaldehyde scavenges cellular glutathione resulting in cytotoxic redox disruption
}

1. Instituto de Investigación en Biomedicina de Buenos Aires (IBioBA), CONICET - Partner Institute of the Max Planck Society, C1425FQD, Buenos Aires, Argentina.

2. Institute for Genome Stability in Ageing and Disease, Medical Faculty, University of Cologne, and Cologne Excellence Cluster for Cellular Stress Responses in Aging-Associated Diseases (CECAD), and Center for Molecular Medicine Cologne (CMMC), 50931 Cologne, Germany.

3. Centro de Investigaciones en Bionanociencias (CIBION), Consejo Nacional de Investigaciones Científicas y Técnicas (CONICET), C1425FQD, Buenos Aires, Argentina.

4. Max Planck Institute for Metabolism Research, Cologne Excellence Cluster on Cellular Stress Responses in Aging-associated Diseases (CECAD), Center for Endocrinology, Diabetes and Preventive Medicine (CEDP), 50931 Cologne, Germany.

5. State Key Laboratory of Brain and Cognitive Science, Institute of Biophysics, Chinese Academy of Sciences, Beijing 100101, China; CAS Key Laboratory of Mental Health, Institute of Psychology, Chinese Academy of Sciences, Beijing 100101, China.

6. These authors contributed equally

*Correspondence: Ipontel@ibioba-mpsp-conicet.gov.ar 


\section{Abstract}

26 Formaldehyde (FA) is a ubiquitous endogenous and environmental metabolite that is thought to exert

27 cytotoxicity through DNA and DNA-protein crosslinking. We show here that FA can cause cellular damage

28 beyond genotoxicity by triggering oxidative stress, which is prevented by the enzyme alcohol dehydrogenase

295 (ADH5/GSNOR). Mechanistically, we determine that endogenous FA reacts with the redox-active thiol group

30 of glutathione (GSH) forming S-hydroxymethyl-GSH, which is metabolized by ADH5 yielding reduced GSH thus

31 preventing redox disruption. We identify the $A D H 5$-ortholog gene in Caenorhabditis elegans and show that

32 oxidative stress also underlies FA toxicity in nematodes. Moreover, we show that endogenous GSH can protect

33 cells lacking the Fanconi Anemia DNA repair pathway from FA, which might have broad implications for

34 Fanconi Anemia patients and for healthy BRCA2-mutation carriers. We thus establish a highly conserved

35 mechanism through which endogenous FA disrupts the GSH-regulated cellular redox homeostasis that is 36 critical during development and aging.

37 Keywords: Glutathione, Formaldehyde, Oxidative Stress, Fanconi Anemia, ADH5, GCLM, p53, S38 hydroxymethylglutathione, Cancer, Genotoxicity.

Introduction

FA is a potent genotoxin classified by the World Health Organization (WHO) as a human carcinogen ${ }^{1}$.

42 In the body, FA can originate from cellular metabolism, i.e. histone and DNA demethylation reactions or the 43 one-carbon cycle; it can also arise from the diet and it is ubiquitously found in the environment ${ }^{2-5}$. Indeed, this

44 aldehyde is more abundant in the body than previously thought; different works have reported FA 45 quantification in healthy human blood samples with levels in the 10-50 $\mu \mathrm{M}$ range ${ }^{6,7}$. Endogenous FA has been 46 suggested as a causative agent for several human diseases such as Fanconi Anemia and the Ruij-Aalfs 47 syndrome, and it might drive cancer in BRCA2-mutation carriers ${ }^{5,8}$. Indeed, Fanconi Anemia patients carrying 48 a mutation in the acetaldehyde/FA metabolizing gene $A L D H 2$ present accelerated progression of bone marrow 49 failure $(B M F)^{9-11}$. Moreover, mice lacking $A D H 5$ and the Fanconi Anemia DNA repair pathway show severe 
BMF, liver and kidney dysfunction and early cancer onset ${ }^{9}$, indicating that endogenous FA can drive cancer initiation and Fanconi Anemia phenotypes.

Genotoxicity has been widely indicated as the main consequence of FA reactivity in cells ${ }^{4}$. However,

53 the strong reactivity of the FA carbonyl group might also affect other molecules than DNA. In vitro, the

54 spontaneous electrophilic attack of the FA carbonyl group to the thiol-group of GSH leads to the formation of

55 the covalent product S-hydroxymethyl-GSH (HSMGSH) $)^{12}$. This reaction might be strongly favored inside cells,

56 where GSH levels are in the millimolar range ${ }^{13}$. Accordingly, ADH5 metabolizes HSMGSH yielding formate,

57 which is directed to the one-carbon cycle for nucleotide synthesis ${ }^{3}$ (Fig. 1A).

Considering the electrophilicity of FA and the abundance of GSH we hypothesize that the reaction

between FA and GSH might affect the GSH pool having detrimental biological consequences. Indeed,

60 alterations in GSH homeostasis have been reported in multiple pathologies such as hemolytic anemia,

61 diabetes, liver diseases, cystic fibrosis, neurodegeneration and cancer ${ }^{14-17}$. GSH not only neutralizes reactive

62 oxygen species (ROS), but can also promote chemoresistance by forming GSH-xenobiotic conjugates that are

63 pumped out of the cell via multiple resistance-associated protein transporters (MRP) $)^{18}$. To replenish

64 intracellular GSH, cells synthesize GSH in a two-step metabolic pathway centered on the rate-limiting enzyme

65 glutamate cysteine ligase (GCL), which is composed of a catalytic (GCLC) and a regulatory (GCLM) subunit, and

66 the GSH synthetase (GS) (Fig. 1a) $)^{18}$. Cells might thus also need to maintain the balance between GSH and the

67 oxidized GSH disulfide form (GSSG) -GSH:GSSG- to limit free FA and to prevent redox disruption.

We report here that FA toxicity is inflicted by the reaction between FA and the redox-active thiol group

69 present in GSH, which disables the antioxidant property of GSH. Our data also support a previously

70 unrecognized function of GSH in the protection against FA toxicity, and an evolutionary conserved mechanism

71 that maintains GSH:GSSG balance by salvaging reduced GSH from FA-GSH covalent adducts. These data might

72 have wide implications not only for Fanconi Anemia patients and BRCA2-mutation carriers but also for cancer

73 cells that would have to overcome blood FA level for a successful disease progression ${ }^{8,9}$. 
Results

ADH5 prevents FA toxicity in human cancer cells

FA levels in blood from different species have been reported in the 10-50 $\mu \mathrm{M}$ range (Reingruber and Pontel, 2018 and references therein). With the aim to determine the amount of FA in blood, we set out to measure this aldehyde in serum samples from 6-month old mice. FA was detected and quantified in mouse blood with a mean concentration of $9.95 \pm 1 \mu \mathrm{M}(\mathrm{n}=14)$, which is in the same order as values reported for

81 healthy human blood ${ }^{6,7}$ (Fig. 1b). In mice, ADH5 limits the toxicity of FA by converting it into the less toxic formate. To address whether cancer cells also rely on ADH5 activity to prevent FA toxicity, we inactivated the ADH5 gene in HCT116 human colorectal carcinoma cells by CRISPR/Cas9 (Extended Data Fig. 1a,b). ADH5deficient cells were not able to form tumor-spheroids in presence of FA, and they became sensitive to levels of FA near to those present in human blood (Extended Data Fig. 1c,d). Moreover, ADH5 prevented the early apoptosis markers Annexin V, a blockage of the cell cycle at G2/M phase and sub-G1 DNA accumulation (Fig. 1e,f and Extended Data Fig. 1c), indicating that ADH5 limits FA-triggered cell death. Consistently, lymphoblastic leukemia Nalm6 cells lacking $A D H 5$ also presented strong sensitivity to blood FA levels, indicating that ADH5 protects unrelated human cancer cells from FA toxicity (Extended Data Fig. 1d).

p53 orchestrates a FA response

Cell death can be a consequence of extensive damage to cellular components such as DNA, which might be detected by cell-fate regulators like $p 53^{19}$. Indeed, p53 has been shown to trigger a cellular response leading to acetaldehyde-mediated cell death in hematopoietic cells deficient in the Fanconi Anemia DNA

94 crosslink repair pathway ${ }^{10}$. We set out to determine whether $\mathrm{p} 53$ could also orchestrate a cellular response to FA in HCT116 cells proficient for DNA repair leading to cell death. Surprisingly, the simultaneous inactivation of $P 53$ and $A D H 5$ only slightly suppressed the cytotoxicity of FA observed in HCT116 $\triangle A D H 5$ cells (Fig. 2a and

97 Extended Data Fig. 1e,f). In contrast, we found that inactivating P53 significantly suppressed the severe colony-formation phenotype detected in $\triangle A D H 5$ cells at FA concentrations as low as $12.5 \mu \mathrm{M}$ but only mildly 
100 dependent and independent pathways. HCT116 cells are proficient for the Fanconi Anemia DNA crosslink

101 repair pathway, which might limit lethal FA genotoxicity. We therefore interrogated whether DNA damage

102 was leading to a p53 response and to the accumulation of the double-strand break marker $\gamma-\mathrm{H} 2 \mathrm{AX}$. We 103 detected $p 53$ phosphorylation, indicative of the activation of p53, in $\triangle A D H 5$ but not in Wild type (WT) cells 104 (Fig. 2c,d and Extended Data Fig. 1e), which correlated with cell cycle blockage at G2/M phase (Fig. 1f). 105 However, we could not detect a significant induction of $\gamma-\mathrm{H} 2 \mathrm{AX}$ by blood-FA levels neither in WT nor in $\triangle A D H 5$ 106 cells (Fig. 2c,d). In contrast to FA treatment, exposure to the DNA-damaging drugs cisplatin, hydroxyurea (HU) 107 or mitomycin C (MMC) resulted in a profound induction of those DNA-damage markers (Fig. $\mathbf{2 c}, \mathbf{d})$. To confirm 108 that a 48-h exposure to micromolar levels of FA is not lethally genotoxic for cells proficient in DNA repair, we 109 addressed genome instability by direct visualization of single chromosome damage (Fig. 2e,f). Indeed, we 110 found that most of the metaphases in WT as well as in $\triangle A D H 5$ cells were normal and only few of them 111 presented chromosome damage. In stark contrast, severe chromosome damage was evident upon treatment 112 with the DNA crosslinking agent mitomycin C, thus suggesting that when DNA repair is functional, FA might be 113 causing cell death by damaging other cellular components than DNA.

\section{Oxidative stress underlies FA cytotoxicity}

With the aim of discovering physiologically relevant cellular targets of FA, we reasoned that the strong

116 avidity of the FA-carbonyl group toward electron-rich thiol groups might affect the antioxidant GSH. Indeed, 117 the reaction between FA and the thiol group in GSH would block the redox capability of GSH, impairing its 118 redox function. Moreover, the abundance of GSH (1-10 mM) might favor the spontaneous reaction between 119 GSH and FA, which, if not limited, could diminish cellular GSH levels leading to oxidative stress. We therefore 120 measured the cellular oxidative status by quantifying the oxidation of the probe $2^{\prime}, 7^{\prime}-$ 121 dichlorodihydrofluorescein diacetate (H2DCFDA). Interestingly, FA induced a significant oxidation of H2DCFDA 122 in $\triangle A D H 5$ cells (Fig. $\mathbf{3 a}, \mathbf{b}$ ). This oxidation level was comparable to that observed when exposing cells to the 123 GSH-synthesis inhibitor L-buthionine-sulfoximine (L-BSO), and could be reverted by expressing ADH5 in trans. 124 In order to test this more thoroughly, we incorporated the genetically-encoded cytosolic ROS sensor roGFP ${ }^{20}$. 
125 Exposure to FA induced a population of cells in which the sensor is oxidized in the absence of $A D H 5$. These results indicate that FA detoxification is necessary to prevent oxidative stress (Fig. 3c,d).

To address the causal contribution of FA-induced oxidative stress to cell death, we set out to test

128 whether cell toxicity could be rescued by the antioxidants $\mathrm{N}$-acetylcysteine (NAC), glutathione monoethyl

129 ester (GSH-MEE) or Trolox (water-soluble vitamin E). The death phenotype and the 3D-sphere formation 130 defect could be almost fully reverted by incubating with GSH-MEE or NAC, indicating that an increase in free131 thiols can prevent FA cytotoxicity (Fig. 3e,f). Remarkably, GSH-MEE and NAC led to an overgrowth of WT 3D132 spheres (Fig. 3f,g). In contrast, Trolox, a non-thiol antioxidant, was unable to limit FA toxicity, suggesting that 133 oxidative stress per se is not sufficient to poison $\triangle A D H 5$ cells (Fig. 3e,f). NAC can work by directly scavenging 134 free FA or by boosting endogenous $\mathrm{GSH}^{21}$. To further interrogate the suppressive effect observed with this 135 thiol-rich antioxidant, we combined L-BSO and NAC. Remarkably, NAC could still rescue the toxicity caused by 136 FA even when GSH synthesis was inhibited by L-BSO (Fig. 3e). However, blocking GSH synthesis limited the 137 overgrowth phenotype observed in 3D-spheres exposed to NAC (Fig. 3e,g). Moreover, GSH synthesis inhibition 138 reduced the NAC-rescue of 3D-sphere formation in $\triangle A D H 5$ cells exposed to FA from $96.5 \%$ to $75 \%$ (Fig. $3 \mathrm{~h}$ ). 139 Altogether, these observations indicate that ADH5 limits oxidative stress induction by FA and that supplying 140 GSH can prevent FA toxicity.

\section{GSH biosynthesis limits FA toxicity}

Exogenous GSH precursors can prevent FA toxicity; we therefore predicted that limiting endogenous

143 GSH should increase FA toxicity even in presence of ADH5. First, we selected concentrations of the GSH 144 synthesis inhibitor L-BSO that were not cytotoxic to the human cancer cells HCT116 and Nalm6 (Extended 145 Data Fig. 2a). The viability of WT HCT116 and Nalm6 cells in presence of FA was significantly reduced in 146 presence of L-BSO, indicating that GSH synthesis contributes to cellular FA tolerance (Fig. 3e,4a). Surprisingly, 147 a non-cytotoxic L-BSO concentration affected the formation of 3D-spheres in both WT and $\triangle A D H 5$ HCT116 148 cells even in absence of exogenous FA (Fig. 4b). In Nalm6 cells, which grow in suspension, the treatment with 149 L-BSO increased the sensitivity of $\triangle A D H 5$ cells to FA (Fig. 4a), suggesting that GSH biosynthesis and ADH5 
independently contribute to prevent FA toxicity in this lymphoblastic human cancer cell. Although L-BSO is neither cytotoxic to HCT116 nor Nalm6 cells at the concentrations used in our experiments (Extended Data

152 Fig. 2a), it is still a pharmacological avenue that might have off-target effects. We therefore set out to 153 genetically inactivate GSH biosynthesis (GCLM) by CRISPR/Cas9 in HCT116 cells (Extended Data Fig. 2b,c,d). 154 Concordantly with the pharmacological experiments, GCLM deficiency reduced cellular tolerance to FA (Fig. 155 4c). The simultaneous inactivation of $A D H 5$ and GCLM did not further affect viability (Fig. 4c). This result 156 indicates that for cell viability, ADH5 is the dominant factor in protecting HCT116 cells against FA. The 3D157 sphere formation phenotype was affected by the sole inactivation of GLCM (Fig. 4d), concordantly with the 158 results observed using the GSH-synthesis inhibitor L-BSO (Fig. 4b). In contrast, the formation of colonies was 159 further impaired in $\triangle G C L M \triangle A D H 5$ cells compared to single knockout counterparts, thus revealing an 160 independent contribution of GSH biosynthesis and ADH5 to this phenotype (Fig. 4e,f). The disparity observed 161 in viability and colony survival assays might indicate that in absence of both $A D H 5$ and GCLM some phenotypes such as cell-cell interaction might be affected without necessarily impairing cell viability. a substrate of ADH5. We hypothesized that this reaction might occur in vivo affecting the endogenous level of GSH as well as limiting the reactivity of free FA. By in house synthesis and reaction monitoring using

167 ultraperformance liquid chromatography coupled to high resolution mass spectrometry (UPLC-HRMS), we first 168 confirmed that GSH and FA react in vitro yielding HSMGSH, which was subsequently used as chemical standard 169 (Extended Data Fig. 3). Should cellular metabolism generate endogenous FA, we might be able to detect the 170 formation of HSMGSH. By UPLC-HRMS, we were able to detect this compound together with GSH and GSSG 171 in cell extracts (Fig. 5b,c and Extended Data Fig. 4a-d). The continuous generation of FA from cellular 172 metabolism might need a constant recovery of reduced GSH from HSMGSH formation to sustain endogenous 173 GSH. Indeed, cells lacking ADH5 presented significantly lower levels of GSH compared to WT cells (Fig. 5d). 174 This decrease is in line with the accumulation of HSMGSH relative to GSH (Fig. 5e). However, the net amount 175 of total GSH and HSMGSH was lower in $\triangle A D H 5$ cells, thus we cannot rule out the participation of efflux 
mechanism(s) pumping out HSMGSH when this product accumulates (Fig. $\mathbf{5 e , f ) . ~ T o ~ c o n f i r m ~ t h a t ~} \triangle A D H 5$ cells

177 present lower levels of GSH, we interrogated GSH by using an indirect fluorescent reagent. According to this assay, cells lacking $A D H 5$ contained $17.9 \%$ less reduced GSH than the WT counterparts, corroborating that in vivo ADH5 significantly contributes to cellular GSH (Fig. 5g). The genetic inactivation of the regulatory component in the rate-limiting step of GSH biosynthesis (GCLM) or the treatment with L-BSO further depleted endogenous GSH in both $\triangle A D H 5$ and WT cells, denoting that the mechanism by which ADH5 contributes to GSH homeostasis is downstream GSH synthesis (Fig. $\mathbf{5 g}$ ).

HSMGSH metabolism prevents GSH:GSSG imbalance

In the cytosol, GSH and GSSG levels have been reported to be around $10 \mathrm{mM}$ and $200 \mathrm{nM}$, respectively, determining a cytosolic $\mathrm{GSH}$ redox potential $\left(\mathrm{E}_{\mathrm{GSH}}\right)$ of $-320 \mathrm{mV}^{13}$. Despite the high level of reduced $\mathrm{GSH}$, a small change in the ratio between the reduced and the oxidized GSH form (GSH:GSSG) can substantially affect $\mathrm{E}_{\mathrm{GSH}}$, 187 thus impairing cellular redox balance ${ }^{22}$. We reasoned that blocking the GSH supply through ADH5 would affect 188 the GSH:GSSG ratio, which might consequently lead to oxidative stress (Fig. 3a,d). We therefore measured relative levels of GSSG in both WT and $\triangle A D H 5$ cells (Fig. $5 \mathrm{~h}$ ) and calculated the GSH:GSSG ratio from UPLC190 HMRS data (Fig. 5i), observing a 5.9-fold reduction in $\triangle A D H 5$ compared to WT cells (Fig. 5i). To interrogate the 191 role of $A D H 5$ in maintaining the GSH:GSSG ratio upon FA stress, we incorporated the cytoplasmic version of 192 the reporter Grx1-roGFP2 ${ }^{23}$ in HCT116 WT and $\triangle A D H 5$ cells. This ratiometric reporter $\left(\lambda_{\mathrm{em}}=510 \mathrm{~nm}\right)$ contains 193 two cysteines that can form a reversible disulfide bond that is in equilibrium with the endogenous GSH:GSSG 194 couple. In a more oxidant environment, the ratio between GSH and GSSG will decrease leading to a more 195 oxidized Grx1-roGFP2 sensor. The fraction of the oxidized sensor (OxD Grx1-roGFP2) can be calculated from 196 the ratio between the Grx1-roGFP2 emission at $\lambda=510 \mathrm{~nm}$ when it is excited at $\lambda=405$ and $\lambda=488 \mathrm{~nm}$ 197 (R405/488) ${ }^{23}$. We found that ADH5 prevented the FA-dependent oxidation of Grx1-roGFP2 in the cytosol (Fig. 198 5j), concordantly with the detection of H2CDFDA and roGFP oxidation (Fig. 3a-d). In summary, these results 199 show that HSMGSH metabolization by ADH5 can prevent cytoplasmic GSH:GSSG imbalance by supplying 200 cellular GSH. 
The role of ADH5 is conserved

In order to interrogate the relevance of GSH metabolism and ADH5 beyond human cancer cells, we explored the presence of genes coding for ADH5-like proteins in the metazoan model Caenorhabditis elegans

(Extended Data Fig. 5a). In the nematode, the uncharacterized gene H24K24.3 codes for the ortholog of the human ADH5 enzyme. Transgenic expression of ADH-5 fused with GFP under the control of the endogenous adh-5 promoter (Ex[ $\left.\left.p_{a d h-5 \mathrm{ADH}-5:: G F P ;} p_{m y o-2} \mathrm{tdTomato}\right]\right)$ presented a ubiquitous cytoplasmic expression in larvae and in the adult nematode (Fig. 6a). To assess whether H24K24.3 participates in the prevention of FA toxicity in worms, we generated a null mutant via CRISPR/Cas9 by introducing multiple stop codons in all three reading frames ${ }^{24}$. Animals lacking H24K24.3 showed an extreme hypersensitivity to FA (Fig. 6b,c), affecting

210 the survival throughout development (Extended Data Fig. 5b), overall indicating that H24K24.3 is the ortholog 211 of $A D H 5$ in C. elegans. We thus refer to H24K24.3 from now on as adh-5. While adh-5(sbj21) mutant C. elegans 212 larvae did not survive FA exposure, a pre-treatment with only $10 \mu \mathrm{M}$ NAC significantly restored survival of 213 adh-5 mutants and also allowed animals to develop into adulthood, assessed $72 \mathrm{~h}$ post FA treatment (Fig. 6b214 d and Extended Data Fig. 5b,c). Conversely, treatment of L1 larvae with a sublethal FA concentration and 215 simultaneous exposure to the prooxidant paraquat (PQ), which generates ROS in C. elegans ${ }^{25}$, severely 216 affected the development of L1 adh-5 larvae (Fig. 6e,f). These results indicate that providing an antioxidant 217 can reduce FA toxicity, while additional oxidative damage increases FA stress in nematodes, strongly 218 supporting our model of oxidative GSH imbalance as a FA-cytotoxic effect.

219 Finally, we reasoned that the reaction between FA and GSH forming HSMGSH molecules and their 220 metabolization by ADH5 might limit free FA. It has been shown that cells lacking the interstrand-crosslinking 221 (ICL)-DNA repair pathway Fanconi Anemia are very sensitive to $F A^{9-11}$. We therefore predict that GSH will be 222 required to prevent FA toxicity in Fanconi Anemia. To assess our hypothesis, we exposed Nalm6 cells deficient 223 in FANCB, a Fanconi Anemia DNA crosslink repair gene, to FA in presence of L-BSO. As predicted, $\triangle F A N C B$ cells 224 were sensitive to FA and this phenotype was largely exacerbated by blocking GSH synthesis (Fig. 6g). 225 Interestingly, cells lacking FANCB were significantly sensitive to GSH inhibition even in absence of FA, which 
might be a consequence of an increase in endogenous free FA, overall suggesting that GSH supply might be fundamental for Fanconi Anemia patients (Fig. 6h).

\section{Discussion}

In this work we reveal that FA can cause cytotoxicity by triggering oxidative stress (Fig. 3a-d),

230 explaining earlier observations of oxidative damage in tissues and cells exposed to FA ${ }^{26,27}$. We determined 231 that FA reacts with GSH, affecting the GSH:GSSG ratio and the cellular redox balance. We describe a conserved 232 mechanism to salvage GSH from FA-GSH covalent products (HSMGSH) limiting FA cytotoxicity not only in 233 cancer cells but also in C. elegans. This pathway is centered on the enzyme ADH5 and it is downstream of the 234 de novo GSH synthesis pathway (Fig. 6i).

At physiological FA concentrations as they occur in human blood, ADH5 is essential for cellular growth and viability (Fig. $\mathbf{1 c}, \mathbf{d}, \mathbf{2} \mathbf{c}, \mathbf{d}$ ). In $\triangle A D H 5$ cells FA treatment triggers p53 activation that accounts for some 237 aspects of the FA response such as proliferation arrest at non-cytotoxic FA concentrations (Fig. 2b), while p53 238 is dispensable for the decline in viability (Fig. 2c) suggesting other cell-fate regulators may trigger FA-induced 239 cell death. It is likely that FA-induced DNA damage upregulates a p53 response that blocks cell cycle at G2/M 240 phase, thus impairing the formation of colonies. However, in presence of functional DNA repair mechanisms, 241 DNA damage would be alleviated before it reaches the threshold required for triggering p53-dependent apoptosis. On the other hand, the FA-induced metabolic disruption might lead to p53-independent cell death. Further research should reveal the identity of the p53-independent mechanisms that respond to FA. produces sufficient FA to react with GSH yielding HSMGSH (Fig. $\mathbf{5 b}, \mathbf{c}$ ). ADH5 restores GSH by metabolizing HSMGSH and thus maintaining the cellular GSH balance to limit oxidative stress. Several factors -in addition

247 to GSH- have been implicated in the cellular protection against oxidative stress, most of them being under the 248 control of the master regulator NRF2 ${ }^{28}$. Upon detecting oxidative stress, the NRF2 partner KEAP1 no longer 249 ubiquitin-labels NRF2 for degradation, resulting in NRF2 stabilization and activation of NRF2-response genes. 250 Indeed, inactivating Keap1 has been shown to rescue a phenotype of diet-induced steatohepatitis reported in 
$251 \mathrm{Adh}^{-/}$mice ${ }^{29}$. NRF2 is a tumor suppressor gene that also controls stem cell fate and the crosstalk between 252 NRF2 and HSMGSH metabolism might have significant consequences beyond cancer.

ADH5 can also metabolize S-nitrosoglutathione (GSNO) producing ammonia and GSH ${ }^{12}$. This enzymatic activity gave origin to the alternative name GSNOR and it has prompted the development of pharmacological inhibitors that might be used for modulating nitric oxide homeostasis in inflammatory diseases ${ }^{30}$. Remarkably, GSH is the common product of the enzymatic activity of ADH5 using either HSMGSH or GSNO as substrates.

Thus, blocking ADH5 might trigger adverse effects such as GSH redox imbalance and increased toxic endogenous FA. On the other hand, GSH biosynthesis has been explored as a therapeutic target to overcome resistance to cancer combinatorial therapies. However, cancer cells can compensate GSH depletion by 260 inducing the thioredoxin (TXN) pathway, which helps to maintain cellular antioxidant capacity ${ }^{31}$, and by 261 maintaining protein homeostasis through deubiquitinating enzymes (DUB) ${ }^{32}$. Since FA was shown to induce a 262 proteotoxic stress response ${ }^{33}$, thus ADH5 inhibition might improve the efficacy of DUB inhibitors and GSH 263 depletors in cancer therapy.

Our findings may have wide implications for the human disease Fanconi Anemia. Metabolic ROS were

265 shown to induce DNA damage in hematopoietic stem cells (HSCs) when they start cycling to exit quiescence, 266 which impairs blood production in Fanca-/- mice ${ }^{34}$. It is known that oxygen can exacerbate chromosome 267 aberrations in lymphocytes from Fanconi Anemia patients ${ }^{35}$. Moreover, the GSH precursor NAC has been 268 shown to improve genome stability in these lymphocytes ${ }^{36}$. It is likely that an increase in ROS as consequence 269 of oxygen exposure would affect GSH pool, thus indirectly leading to accumulation of FA and genome 270 instability. A combined therapy using a FA sponge such as metformin ${ }^{37}$ and GSH-precursors might succeed in 271 benefiting Fanconi Anemia patients. Furthermore, a diet rich in GSH-precursors might delay cancer onset in 272 healthy BRCA2-mutation carriers by limiting FA toxicity, overall highlighting the broad reach of the findings 273 reported here.

\section{Methods}

\section{Experimental Model and Subject Details}




\section{Cells and animals}

HCT116 cells were maintained in Dulbecco's Modifies Eagle's Medium (DMEM) high glucose (Thermo Scientific, \#12100061), supplemented with $1 \%$ Penicillin/Streptomycin and $10 \%$ FBS (Natocor) ${ }^{38}$. Nalm6 cells were maintained in Roswell Park Memorial Institute 1640 medium (RPMI) (Thermo Scientific, \#31800105) ${ }^{3}$ containing $10 \%$ FBS, $1 \%$ Penicillin/Streptomycin and $50 \mu \mathrm{M}$ ß-mercaptoethanol. All the cell lines were regularly tested for mycoplasma infection. district president of Cologne. All procedures were approved and authorized by the LANUV with identification number 84-02.04.2015.A484. 'Role of ageing-associated DNA damage in energy homeostasis-regulating neurons. Mice were maintained in individually ventilated cages (IVCs) on autoclaved bedding and food and sterile-filtered water in a barrier facility at the University of Cologne and the MPI for Metabolism Research. Mice were subjected to a constant $12-\mathrm{h}$ day-night cycle and a constant room temperature of $22^{\circ} \mathrm{C}$. Starting from 2 months of age, mice were fed a control diet (CD) consisting of $67 \mathrm{~kJ} \%$ carbohydrates, $20 \mathrm{~kJ} \%$ proteins and $13 \mathrm{~kJ} \%$ fat (Sniff). Mice had ad libitum excess to food and water. The NPY-GFP mice were backcrossed for at least two generations to the $\mathrm{C} 57 \mathrm{BL} / 6 \mathrm{~N}$ background ${ }^{39}$.

Caenorhabditis elegans was maintained using standard methods ${ }^{40}$. N2, Bristol C. elegans wild isolate was obtained from Caenorhabditis Genetics Center (CGC), Minneapolis, MN, USA.

HCT116 $\triangle A D H 5, \triangle G C L M, \triangle P 53 \triangle A D H 5$ and $\triangle G C L M \triangle A D H 5$ cell lines were generated by targeting exon 3 of ADH5 (sgRNA: TGCTGGAATTGTGAAAGTGTT) and exon 1 of GCLM (sgRNA: ACGGGGAACCTGCTGAACTG) in the corresponding parental cell lines. Briefly, sgRNAs were cloned into the pX458 vector (Addgene, \#48138) and transfected using lipofectamine 3000 (Thermo Scientific, L3000015). GFP-expressing cells were sorted and 298 clonally diluted in 96-well plates. After 20 days, cells were expanded, and inactivation of the desire gene 299 confirmed by western blot using GCLM (Atlas antibodies, \#HPA023696) or ADH5 antibodies ${ }^{9}$. The mutations 300 generated by Cas9 at the target exons were obtained by preparing genomic DNA from the selected clones and 
302 CCTTCAGCTTAGTAACTC -3' for ADH5, and Fwd (hGCLM-ck_834Fw): 5'-GAAGCACTTTCTCGGCTACG -3'; Rv 303 (hGCLM-834_Rv): 5'-TCCTTTACCTGGACAGGGTG-3' for GCLM. PCR results were analyzed by gel 304 electrophoresis, cloned and sequenced using universal M13 primers.

\section{Generation of cells stably expressing ADH5}

Cells carrying the ADH5-expressing plasmid pLox-ADH5-FLAG-CT-BSR were selected using $4 \mu \mathrm{g} / \mathrm{ml}$

Blasticidin (BSR). BSR-resistant cells were clonally diluted and ADH5-expression verified by western blot against FLAG epitope.Cells carrying the ADH5-expressing plasmid pLox-ADH5-FLAG-CT-BSR were selected using $4 \mu \mathrm{g} / \mathrm{ml}$ Blasticidin (BSR). BSR-resistant cells were clonally diluted and ADH5-expression verified by

310 western blot against FLAG epitope (Abcam, \#ab49763).

\section{Generation of $C$. elegans lines}

The ADH-5::GFP reporter line Ex[ $\left.\mathrm{p}_{a d h-5 \mathrm{ADH}-5:: G F P ;} \mathrm{p}_{\text {myo-2 }} \mathrm{tdTomato}\right]$ was produced via co-injecting the

313 clone (5736523864883943 G06, tagged gene: H24K24.3) of the TransgeneOme fosmid library ${ }^{41}$ together with

314 the selection marker for tdTomato expression in the pharynx, using standard C. elegans microinjection ${ }^{42}$. For

315 imaging, various stages of the transgenic animals were mounted on $5 \%$ agar pads with polystyrene

316 nanoparticles (Polysciences, $2.5 \%$ by volume) as previously described ${ }^{43}$ and imaged at an Axiolmager M.2

317 fluorescence microscope (Zeiss, Jena, Germany).

318 The $C$. elegans orthologue of human adh-5 gene (H24K24.3) was knocked out using the CRISPR/Cas9

319 system as previously reported: The preassembled CRISPR/Cas9 ribonucleoprotein complexes and linear single

320 stranded DNAs as repair templates were directly injected into the gonad of young adult hermaphrodites ${ }^{44}$. To

321 generate $a d h-5$ null mutant, we utilized a universal STOP-IN cassette that contained an exogenous Cas9 target

322 site, multiple stop codons in all three reading frames and the recognition site of the Nhel restriction enzyme

$323{ }^{24}$. The $C$. elegans adh-5 sgRNA with GGG protospacer adjacent motif was designed using Benchling

324 (https://benchling.com/) and targeted exon 3 of the adh-5 gene (5'-CTTCATGTCCCAAGACGACA-3'). The C.

325 elegans DNA repair oligo included a STOP-IN cassette and two short homology arms identical to the sequences

326 flanking the cleavage $\quad$ site $\quad\left(5^{\prime}\right.$ -

327 GCCACACGGACGCCTACACCCTCGACGGACACGATCCGGAAGGTCTCTTCCCTGTGGGAAGTTTGTCCA 
329 facilitate screening, a co-conversion strategy with dominant phenotypic roller marker was used ${ }^{45}$. 330 Microinjection was performed as previously described ${ }^{42}$ using the following injection mix: $\mathrm{KCl}(25 \mathrm{mM})$, Hepes $331 \mathrm{pH} 7.4(7.5 \mathrm{mM})$, tracrRNA $(200 \mathrm{ng} / \mu \mathrm{l}), d p y-10 \mathrm{crRNA}(150 \mathrm{ng} / \mu \mathrm{l}), d p y-10 \mathrm{ssODN}(13.75 \mathrm{ng} / \mu \mathrm{l})$, adh-5 sgRNA

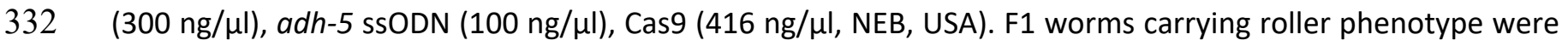
333 preselected and cloned 4-6 days after the injection. The F2 progeny was subsequently screened for the desired 334 edit by PCR amplification using the adh-5 forward primer (5'- CGATCCAAGTGGCTCCACCGAA-3') and the 335 adh-5 reverse primer (5'- TTCCACATCCCAAAAGCGAAACC -3'). The presence of the STOP-IN cassette was 336 verified via Sanger sequencing (Eurofins Genomics, Germany) with the adh-5 sequencing primer (5'337 CGATTAACCGACACCCTTGCTC-3').

\section{Survival and development assays in C. elegans}

For the combined N-acetylcysteine (NAC, Sigma-Aldrich, \#A7250) and formaldehyde (FA, Pierce, \#28908) treatment worm stages were first synchronized via bleach-synchronization. Gravid adult animals and eggs were harvested from NGM plates with $5 \mathrm{ml}$ M9 buffer $\left(3 \mathrm{~g} \mathrm{KH}_{2} \mathrm{PO}_{4}, 6 \mathrm{~g} \mathrm{Na} 2 \mathrm{HPO}_{4}, 5 \mathrm{~g} \mathrm{NaCl}\right.$, in 1 I $\mathrm{H}_{2} \mathrm{O}$; autoclaved and added $1 \mathrm{ml} 1 \mathrm{M} \mathrm{MgSO}_{4}$ ) using a cell scraper and transferred to $15 \mathrm{ml}$ tubes, before adding 1 $\mathrm{ml}$ bleach solution ( $5 \mathrm{M} \mathrm{NaOH}$ and sodium hypochlorite in a 1:1 ratio). The tubes were then constantly vortexed for $5 \mathrm{~min}$ and centrifuged (Centrifuge 5810R, Eppendorf) at $2800 \mathrm{rpm}$ for $1 \mathrm{~min}$. After removing the supernatant, the worms were washed three times with $5 \mathrm{ml} \mathrm{M9}$ medium by shaking the tubes and then centrifuging at $2800 \mathrm{rpm}$ for $1 \mathrm{~min}$. Finally, they were kept in $10 \mathrm{ml} \mathrm{M9}$ medium overnight (16 h) under rotation at $35 \mathrm{rpm}$ (Multiple-Axle-Rotating-Mixer RM10W-80V, CAT) to allow animals to hatch. Prior to FA treatment,

349 The number of worms was determined under a stereoscope in a representative volume of $3 \mu$ and a final 350 concentration of approx. 50-100 worms per $\mu$ l was adjusted. A solution was prepared by pelleting a saturated 351 OP50 E. coli bacterial culture, which was first heat-inactivated $\left(60^{\circ} \mathrm{C} \mathrm{O} / \mathrm{N}\right)$, at $4000 \mathrm{rpm}$ for 10 minutes, and 352 then concentrated two-fold in $\mathrm{M} 9$ plus cholesterol $(5 \mu \mathrm{g} / \mathrm{ml}) .5 \mathrm{ml}$ aliquots were prepared and 1000 worms were added in a volume of 10-20 $\mu \mathrm{l}$. NAC ( $500 \mathrm{mM}$ stock solution in $\mathrm{H}_{2} \mathrm{O}$ ) was added to a final concentration 
354 of $10 \mathrm{mM}$ to half of the aliquots and incubated under rotation for $2 \mathrm{~h}$. Thereafter, various concentrations of

355 FA (10 mM and $12 \mathrm{mM}$ ) were added to the tubes and incubated under rotation for another $4 \mathrm{~h}$. To this end, 356 methanol-free $16 \% \mathrm{FA}$ (w/v; Thermo Scientific) was first adjusted to a $1 \mathrm{M}$ stock solution in $\mathrm{H}_{2} \mathrm{O}$, which was 357 prepared fresh for each experiment. After the NAC/FA treatment, the solutions were centrifuged at $1300 \mathrm{rpm}$ 358 for 1 minute, followed by two washing steps with $5 \mathrm{ml} \mathrm{M9}$ medium. Finally, worms were pelleted again and 359 the volume was reduced to $500 \mu \mathrm{l}$. A volume of 25-50 $\mu \mathrm{l}$ (approx. 50-100 worms) was transferred to OP50360 seeded NGM plates, on which the survival rate was scored under a stereoscope. Worms were qualified as 361 dead when no locomotion could be detected and when stimulation with a wormpick did not cause a response. 362 The survival count was repeated after $24 \mathrm{~h}, 48 \mathrm{~h}$ and $72 \mathrm{~h}$. In parallel, developmental stages of worms were 363 determined under the stereoscope at $48 \mathrm{~h}$ and $72 \mathrm{~h}$ post-treatment and qualified in the categories L1-L3, L4 364 and adult.

The combined PQ and FA treatment was performed in the same way as the NAC/FA treatment, with 366 the exception that PQ was added at the same time as FA ( $2 \mathrm{mM})$ and incubated together for a total of $5 \mathrm{~h} . \mathrm{PQ}$ 367 (Methyl viologen dichloride hydrate, Sigma-Aldrich, \#856177) was always freshly prepared and first adjusted to a $1 \mathrm{M}$ stock in $\mathrm{H}_{2} \mathrm{O}$, which was further diluted for the treatment.

\section{Viability and survival assays}

For determining cell viability, cells were seeded into 96-well plates at a density of 3000 cells per well 371 and allowed to attach for $24 \mathrm{~h}$ at $37^{\circ} \mathrm{C}, 5 \% \mathrm{CO}_{2}$. Then, $\mathrm{FA}$ and/or L-buthionine-sulfoximine (L-BSO, Sigma372 Aldrich, \#B2515) and/or antioxidants were added to a final volume of $200 \mu$ l per well. 3 days later, resazurin 373 (Sigma-Aldrich, \#R7017) was added to a final concentration of $30 \mu \mathrm{M}$ in the growing medium. Fluorescence $374\left(\lambda_{\mathrm{ex}}=525 \mathrm{~nm} ; \lambda_{\mathrm{em}}=590 \mathrm{~nm}\right)$ was measured $3 \mathrm{~h}$ later in an Enspire Plate Reader (Perkin Elmer). For Nalm6, 3755000 cells per well were seeded into 96-well plates and the drugs to be tested added immediately afterward. 376 Viability was determined 5 days later. In all cases, the experiments were done by triplicate and data 377 represented as percentage of the fluorescence obtained with the untreated samples of the corresponding cell 378 line. 
The colony survival assay was done by seeding 600 cells per well in 6-well plates. Immediately

380 afterward, FA was added at the concentrations described in the text in a final volume of $2 \mathrm{ml}$ (DMEM). Plates were maintained during $7-10$ days at $37^{\circ} \mathrm{C}, 5 \% \mathrm{CO}_{2}$. Staining was done using a fixative/staining solution $(0.5$ $\%$ crystal violet, $6 \%$ glutaraldehyde) for 30 minutes, following of extensive rinse with tap water. Visible colonies were counted, and the results expressed as percentage of the untreated wells. Experiments were done by duplicated and repeated the number of times indicated in each corresponding figure.

\section{ROS measurement by H2DCFDA}

ROS measurement was performed using 2',7'-dichlorodihydrofluorescein diacetate (H2DCFDA, Sigma-

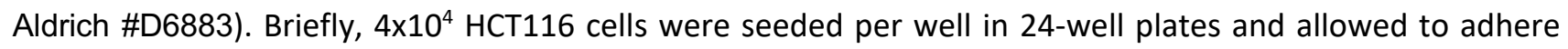
overnight. Cells were then treated with 0,60 and $150 \mu \mathrm{M}$ of FA and 0 or $100 \mu \mathrm{M}$ of L-BSO, for $48 \mathrm{~h} . \mathrm{H}_{2} \mathrm{O}_{2} 500$ $\mu \mathrm{M}$ was used as a positive control and added 15 minutes prior H2DCFDA staining. After treatment, H2DCFDA was added to each well at a final concentration of $10 \mu \mathrm{M}$, kept 30 min at $37^{\circ} \mathrm{C}$. Then, cells were lifted and transferred to flow cytometry tubes, which were kept at $4^{\circ} \mathrm{C}$ until measuring was performed. Fluorescence

$\left(\lambda_{\text {ex }}=488 \mathrm{~nm} ; \lambda_{\mathrm{em}}=530 \mathrm{~nm}\right)$ was measured by flow cytometry using a Becton Dickinson's FACS Canto II Flow cytometer.

\section{ROS and GSH redox status determination by genetic sensors}

The cytosolic roGFP2 sensor was cloned from Addgene 49435 into a retroviral backbone pLPCX by

Gibson Assembly. Plasmid sequence was confirmed by sequencing. Retroviral infection was carried out transfecting HEK293T cells with pBS-CMV-gagpol (Addgene, \#35614) and pCAG-VSVG (Addgene, \#35616) vectors in addition to pLPCX cyto Grx1-roGFP2 (Addgene, \#64975) or pLPCX cyto roGFP (Addgene, \#49435). $400 \quad)(1 \mu \mathrm{g} / \mu \mathrm{L})$. Infection was confirmed by GFP-expression (90\% efficiency). Cells expressing the desired reporter 401 were selected with $0.5 \mu \mathrm{g} / \mathrm{mL}$ puromycin. No clonal selection was carried out to prevent single clone artefacts. 402 For ROS measurement, cells were seeded into a 24 -well plate at $3.5 \times 10^{4}$ cells per well and allowed to adhere 403 overnight. Cells were then treated with 0,60 and $150 \mu \mathrm{M}$ of $\mathrm{FA}$, and $\mathrm{O}$ or $100 \mu \mathrm{M}$ of L-BSO, for 48 h. $\mathrm{H}_{2} \mathrm{O}_{2} 500$ $404 \mu \mathrm{M}$, which was used as a positive control, was added 15 minutes prior cell analysis. After treatment, culture 
405 media was removed, and cells were washed with PBS. Cells were then trypsinized and transferred into clear 406 flow cytometry tubes containing phosphate buffer saline (PBS) supplemented with $2 \%$ fetal bovine serum 407 (FBS). Tubes were kept at $4^{\circ} \mathrm{C}$ until measuring was performed. Fluorescence $\left(\lambda_{\mathrm{ex}}=405 \mathrm{~nm}\right.$ and $488 \mathrm{~nm}, \lambda_{\mathrm{em}}=$ $408510 \mathrm{~nm}$ ) was measured by flow cytometry using a Becton Dickinson's FACS Aria II flow cytometer.

409 For determination of the glutathione (GSH) redox potential, cells expressing pLPCX cyto Grx1-roGFP2 were 410 exposed to FA and/or L-BSO for $48 \mathrm{~h}$. Then, cells were collected and fluorescence $\left(\lambda_{\mathrm{ex}}=405 \mathrm{~nm}\right.$ and $488 \mathrm{~nm}$, $411 \lambda_{\mathrm{em}}=510 \mathrm{~nm}$ ) determined by flow cytometry as described above ${ }^{23}$. The fraction of oxidized Grx1-roGFP2 412 sensor was calculated using the formula:

$$
O x D_{\text {roGFP2 }}=\frac{R-R_{\text {red }}}{\left(\frac{I_{488 \text { min }}}{I_{488 \text { max }}}\right) x\left(R_{o x}-R\right)+\left(R-R_{\text {red }}\right)}
$$

\section{Metaphases analysis}

To assess single-chromosome damage, HCT116 Wild type (WT) and $\triangle A D H 5$ cells were plated in P60 dishes allowed to adhere and then treated with mitomycin C (MMC, Santa Cruz, \#sc-3514) $0.5 \mu \mathrm{g} / \mathrm{ml}$ during

$41724 \mathrm{~h}$ or with FA $150 \mu \mathrm{M}$ during $48 \mathrm{~h} .16 \mathrm{~h}$ before harvesting the cells Colcemid (Gibco, \#15212-012) was added 418 at the concentration of $0.08 \mu \mathrm{g} / \mathrm{ml}$ without replacing the culture medium. Cells were washed with PBS and 419 trypsin added to a final concentration of $0.125 \%$. Complete medium was added to stop trypsin reaction and 420 clumps of cells disrupted by pipetting. Then, cells were centrifuged and resuspended into $2 \mathrm{ml}$ of prewarmed 421 hypotonic solution $(\mathrm{KCl} 0.075 \mathrm{mM})$ and incubated in $14 \mathrm{ml}$ of this solution for 15 minutes at $37^{\circ} \mathrm{C}$. Then, $1 \mathrm{ml}$ 422 of fixative solution was added (3:1 methanol:glacial acetic acid) dropwise. Cells were washed twice with 423 fixative solution and then dropped onto chilled humid slides, where cells were left to dry overnight. The day 424 after, slides were stained in $2 \%$ Giemsa solution (Thermo Scientific, \#10092013) prepared in Gur buffer (Gibco, $425 \# 10582-013)$, left to dry and mounted using BC solution (Cicarelli, \#891). Pictures were taken using a Zeiss 426 Axiobserver Z1 microscope with a 40x oil-immersion objective and analyzed using Image $\mathrm{J}^{46}$. To guarantee 427 unbiased quantitation, pictures were taken by a microscopy technician, who labeled the images with numbers. After scoring of chromosome damage, the identities of the images were revealed. 
43196 -well plates were coated with $50 \mu \mathrm{L}$ of $1.5 \%$ sterile agarose $2 \mathrm{~h}$ before cell plating. $100 \mu \mathrm{l}$ of HCT116 cells 432 (WT, $\triangle A D H 5, \triangle A D H 5$ complemented, $\triangle G C L M$ or $\triangle A D H 5 \triangle G C L M$ ) were seeded at a concentration of $2 \times 10^{3}$ or $4334 \times 10^{3}$ cells/well. Immediately after seeding, cells were treated with $100 \mu$ l of DMEM $10 \%$ FBS containing $2 x$ 434 concentrations of the drugs used. The final concentrations of the drugs were $0,50,100$ and $150 \mu \mathrm{M} F \mathrm{~A} ; 0$ and $435100 \mu \mathrm{M}$ L-BSO; 0 and $500 \mu \mathrm{M}$ NAC; 0, 1 mM Glutathione monoethyl ester (GSH-MEE, Santa Cruz, \# SC-203974); 4360 and $1 \mathrm{mM}$ Trolox (Sigma-Aldrich, \#\#238813). Plates were kept at $37^{\circ} \mathrm{C}$. Spheroid formation was assayed by 437 microscopy (Zeiss Axio A1 inverted microscope) 5-7 days after seeding and registered using a CANON Rebel 438 T3i camera attached to the microscope with an appropriate adaptor, at 40x magnification. For sphere-size 439 quantification Fiji was used to measure the area of the formed sphere.

\section{Phylogenetic analysis}

Eukaryote orthologs of ADH5 were obtained from NCBI, CLUSTAL at phylogeny.fr was used to align the sequences and TreeDyn at phylogeny.fr for tree generation ${ }^{47}$.

Western blot analysis 447 protease inhibitor mixture (Roche, \#COEDTAF-RO), and phosphatase inhibitor mixture (Roche, $448 \#$ \#4906837001). Samples were bath-sonicated (3 pulses 30" ON 30" OFF) and boiled for 10 minutes. Sample 449 concentration was relativized by Coomassie Brilliant Blue staining. For separation, samples were loaded onto $45012 \%$ polyacrylamide gels and subjected to electrophoresis. Protein was transferred to nitrocellulose 451 membranes, which were blocked with $2 \%$ BSA in Tris-buffered saline (TBS) or $5 \%$ non-fat milk in TBS. 452 Membranes were incubated with primary antibodies overnight at $4^{\circ} \mathrm{C}$, followed by incubation with secondary 453 antibodies conjugated with either horseradish peroxidase or fluorescent dye. DNA damaging agents were 454 MMC, cisplatin (Santa Cruz, \#sc-200896) and Hydroxyurea (Santa Cruz, \#sc-29061) Proteins were visualized 455 using ECL prime chemiluminescence reagent or fluorescence emission, respectively. Primary antibodies used 
were p53 (CST, \#9282), phospho-P53 (CST, \#9284), p21 (CST, \#2947), phospho-histone H2A.X (CST, \#9718), Vinculin (Santa Cruz, \#sc-73614), alpha-tubulin (CST, \#2144), and beta-actin (Santa Cruz, \#sc-47778). Secondary antibodies used were horseradish peroxidase-linked anti-rabbit (CST, \#\#7074), horseradish peroxidase-linked anti-mouse (CST, \#7076), DyLight-800 4x PEG-linked anti-rabbit (CST, \#5151), and DyLight 680-linked anti-mouse (CST, \#5470).

\section{Cell cycle assay and apoptosis determination}

Cells were plated at a final concentration of $3 \times 10^{5}$ cells per well in DMEM supplemented with $10 \% \mathrm{FBS}$.

After $24 \mathrm{~h}$, cells were treated with 0,60 , and $150 \mu \mathrm{M}$ FA for $24 \mathrm{~h}$. After this period, cells were harvested by

464 trypsinization and pelleted by centrifugation ( $5 \mathrm{~min}, 1000 \mathrm{xg}$ ). Cells were washed with cold PBS and then fixed 465 with $70 \%$ cold ethanol for 15 min on ice. Cells were washed twice with PBS and treated with $30 \mu \mathrm{g}$ 466 ribonuclease A and $15 \mu \mathrm{g}$ of propidium iodide. Cells were run on a BD FACS Canto II flow cytometer and the 467 data was analyzed with FlowJo 10.0.7 (Tree Star). For apoptosis determination, the BD PE Annexin V Apoptosis 468 Detection Kit (BD Pharmigen, \#579563). Briefly, cells were plated and $24 \mathrm{~h}$ later exposed to the indicated 469 concentrations of FA. 24 h later, cells were lifted, washed with cold PBS and stained with PE-Annexin V 470 antibody and 7-AAD. Samples were run on a BD FACSAria II flow cytometer and data analyzed with FlowJo $471 \quad 10.0 .7$ (Tree Star).

\section{GSH measurement}

GSH was determined using the GSH-Glo'm Glutathione Assay (Promega, \#V6911). Briefly, 10000 cells per

474 well were seeded in a 96-well plate. A duplicated plate was prepared to determine viability. $48 \mathrm{~h}$ later GSH

475 was determined following the instructions provided in the kit. In parallel, the viability was scored using 476 resazurin and the results adjusted for the percentage of viable cells relative to the GSH content of WT cells.

\section{$477 \quad$ Formaldehyde determination in blood}

Mice were sacrificed at 6 months of age by decapitation, full blood was collected, and serum was 479 separated from red blood cells by centrifugation $\left(15,000 \times \mathrm{g}, 30 \mathrm{~min}, 4^{\circ} \mathrm{C}\right)$. Serum was transferred to a new 480 Eppendorf tube and sera of three mice of the same age, sex and diet were pooled and subsequently subjected 481 to trichloroacetic acid (Guoyao, \#80132618) (20\% w/v, in ultrapure water) precipitation. Therefore, 
trichloroacetic acid was added in a 1:1 ratio to the serum, vortexed for $30 \mathrm{sec}$. and centrifuged $(15,000 \times \mathrm{g}, 30$ $\min , 4^{\circ} \mathrm{C}$ ). The supernatant was transferred to a fresh Eppendorf tube and stored at $-80{ }^{\circ} \mathrm{C}$ until further processing.

The concentration of FA was detected by high-performance liquid chromatography (HPLC) as previously described $^{48}$. Serum samples $(0.08 \mathrm{ml}$ each) were mixed with $0.02 \mathrm{ml} 10 \%$ trichloroacetic acid, $0.08 \mathrm{ml}$ acetonitrile (Thermo Scientific, \#A998-4), and $0.02 \mathrm{ml}$ 2,4-dinitrophenylhydrazone (Beijingshiji, \#550626). Samples were centrifuged $\left(15,000 \times \mathrm{g}, 4^{\circ} \mathrm{C}, 10 \mathrm{~min}\right)$ and then reacted in a $60^{\circ} \mathrm{C}$ water bath for $30 \mathrm{~min}$; this step was followed by a centrifugation $\left(15,000 \times \mathrm{g}, 4{ }^{\circ} \mathrm{C}, 10 \mathrm{~min}\right)$ and filtered $(0.22 \mu \mathrm{m}) .20 \mu$ of the solution was then subjected to HPLC (LC-20A, Shimadzu, Japan). FA-DNPH derivatives were detected with an ultraviolet detector (Cas: 228-34016, Shimadzu, Japan) and a C18 reversed-phase column (Sigma-Aldrich, \#50208-U), using $65 \%$ acetonitrile as the mobile phase.<smiles>NC(CCC(=O)NC(CS)C(=O)NCC(=O)O)C(=O)O</smiles><smiles>O=CC1CCCCC1</smiles><smiles>NC(CCC(=O)NC(CSCO)C(=O)NCC(=O)O)C(=O)O</smiles>

Procedure:

498 In a $50 \mathrm{ml}$-bottom flask, FA solution (12 $\mu \mathrm{L}, 37 \mathrm{wt}$. \% in water, Sigma-Aldrich, \#F8775) and $\mathrm{HCl}(0.5 \mathrm{ml}, 36.5-$ $49938.0 \%$ ) were dissolved in $2 \mathrm{ml}$ of dioxane (Sintorgan, \#SIN-083003-63). The mixture was stirred at room 500 temperature over $5 \mathrm{~min}$ and glutathione (Santa Cruz, \#sc-29094) (50 mg, $0.16 \mathrm{mmol}$ ) was added in small 501 portions. After stirring at room temperature over $48 \mathrm{~h}$, the mixture was neutralized with saturated aqueous $\mathrm{NaHCO}_{3}$ solution and partitioned between ethyl acetate and water. The aqueous phase was lyophilized (0.03 $\mathrm{mBar},-80^{\circ} \mathrm{C}, 72 \mathrm{~h}$ ) to obtain a white solid using a Telstar LYOQuest-85 freeze dryer (Telstar, Madrid, Spain). A portion of $10 \mathrm{mg}$ of the solid was resuspended in $1 \mathrm{ml}$ of a $\mathrm{CH}_{3} \mathrm{OH}: \mathrm{CH}_{3} \mathrm{CN}(1: 1)$ mixture, centrifuged and the supernatant was diluted to be analyzed by UPLC-HRMS. Estimated reaction yield $95.8 \%{ }^{49}$. 


\section{Sample preparation for UPLC-HRMS analysis}

507 HCT116 WT and $\triangle A D H 5$ cells were counted and cultured in $100 \mathrm{~cm}$ plates at $1 \times 10^{6}$ cells/plate. Two

508 independent rounds of sample preparation were carried out in consecutive weeks. 6 plates in the first week 509 and 5 plates in the second week for each cell line were set up and allowed to grow for $72 \mathrm{~h}$. One plate in each 510 round was used for protein and cell count. Once $80 \%$ confluence was reached, cells were gently washed with

$5115 \mathrm{ml}$ of a $0.9 \% \mathrm{NaCl}$ aqueous solution at $0{ }^{\circ} \mathrm{C}$. Subsequently, enzymatic activity was quenched by adding liquid

$512 \mathrm{~N}_{2}$. Cells were scrapped immediately after with $1.4 \mathrm{ml}$ of a cold $\left(0^{\circ} \mathrm{C}\right) \mathrm{CH}_{3} \mathrm{OH}: \mathrm{CH}_{3} \mathrm{CN}(50: 50 \mathrm{v} / \mathrm{v})$ solution and

513 subsequently frozen using liquid $\mathrm{N}_{2}$. After one freeze-thaw cycle, samples were vortex-mixed during $30 \mathrm{~s}$ and

514 centrifuged at $5000 \times g$ for $5 \mathrm{~min}$ at $4{ }^{\circ} \mathrm{C}$. Supernatants were collected and stored at $-20{ }^{\circ} \mathrm{C}$ for $2 \mathrm{~h}$ and

515 subsequently centrifuged at $15000 \times \mathrm{g}$ for $10 \mathrm{~min}$ at $4{ }^{\circ} \mathrm{C}$. Afterwards, $1.4 \mathrm{ml}$ of ultrapure water was added to

516 supernatants and these solution were immediately frozen and stored at $-80^{\circ} \mathrm{C}$ until lyophilization.

517 Process blanks consisting of incubating culture media in plates without cells were generated in parallel with 518 samples, and followed the same protocol described above. For protein and cell count, cells were lifted and 519 counted using trypan blue as viability marker. Afterwards, cells were lysed in a solution containing $1 \mu \mathrm{M}$ EDTA; $52010 \mu \mathrm{M}$ Tris $\mathrm{pH} 8 ; 200 \mu \mathrm{M} \mathrm{NaCl}$ and $0.2 \%$ Triton, and total protein was determined by the Bradford assay using 521 BSA as standard. Samples were lyophilized at $-80^{\circ} \mathrm{C}$ and $50 \mathrm{mTorr}$ for $48 \mathrm{~h}$ using a Telstar LYOQuest- 85 freeze 522 dryer (Telstar, Madrid, Spain) and stored at $-80^{\circ} \mathrm{C}$ until analysis by UPLC-HMRS. All sample residues from each 523 batch were reconstituted the same day in a water: methanol $(90 / 10 \mathrm{v} / \mathrm{v})$ solution. Reconstitution factors were 524 selected to reach the same protein content for all samples. After reconstitution, samples were vortex-mixed 525 for $30 \mathrm{~s}$ and centrifuged at $21382 \times \mathrm{g}$ for $20 \mathrm{~min}$ and $4{ }^{\circ} \mathrm{C}$. Supernatants were stored until use at $-80^{\circ} \mathrm{C}$. Quality 526 control (QC) samples were prepared by pooling an aliquot of $15 \mu \mathrm{L}$ from each sample, vortex-mixed for $30 \mathrm{~s}$, 527 split into 4 micro tubes, and stored at $-80{ }^{\circ} \mathrm{C}$ until use for analysis.

528 A pooled QC sample spiked with GSH $(14.3 \mu \mathrm{M})$, GSH disulfide $(15.5 \mu \mathrm{M})$ and S-hydroxymethylglutathione $(20$ $529 \mu \mathrm{M}$ ) was used to verify the stability of retention times, peak shapes and areas during the analysis.

\section{UPLC-HRMS analysis}


531 UPLC-HMRS analyses were performed using a Waters ACQUITY UPLC I Class system fitted with a Waters 532 ACQUITY UPLC BEH $C_{18}$ column $(2.1 \times 100 \mathrm{~mm}, 1.7 \mu \mathrm{m}$ particle size, Waters Corporation, Milford, MA, USA, catalog \#186002352), and coupled to a Xevo G2S QTOF mass spectrometer (Waters Corporation, Manchester,

534 UK, SN: YDA 375) with an electrospray ionization (ESI) source operated in ESI positive ionization mode. The typical resolving power and mass accuracy of the Xevo G2S QTOF mass spectrometer were 32,000 FWHM and $0.3 \mathrm{ppm}$ at $\mathrm{m} / \mathrm{z} 556.2771$, respectively. The mobile phase consisted of water with $0.1 \%$ formic acid (Fisher Chemical, \#F/1900/PB15) (mobile phase A) and methanol (Fisher Chemical A454-4, (UN 1230-CL3)) (mobile phase B). The flow rate was constant at $0.3 \mathrm{ml} \mathrm{min}^{-1}$, the elution gradient was set as follows: 0-1.6 min 0-0\% B; $1.6-2 \min 0-20 \%$ B; 2-6 $\min 20-70 \%$ B; 6-7 $\min 70-70 \%$ B; 7-14 $\min 70-90 \%$ B; $14-17.5 \min 90-90 \%$ B; $17.5-$ 18 min $90-95 \%$ B; $18-21$ min 95-95 \% B. After each sample injection, the gradient was returned to its initial conditions in $9 \mathrm{~min}$ (total run time was $30 \mathrm{~min}$ ). The eluates from the analytical column were diverted by automatically switching the valve to waste, except for the elution window from 0 to $8 \mathrm{~min}$. The column and autosampler tray temperatures were set at 35 and $5^{\circ} \mathrm{C}$, respectively. The injection volume was $2 \mu \mathrm{L}$. A solvent blank, which consisted of a water : methanol $(90: 10 \mathrm{v} / \mathrm{v})$ solution, and a process blank were analyzed at the beginning and end of each batch. Samples were randomly analyzed within a defined template of spiked QC samples, and the analysis order was balanced based on sample classes. QC samples were used to condition the LC-MS system before sample analysis. A total of 20 randomized samples (WT cells $\mathrm{n}=10$ and $\triangle A D H 5$ cells $\mathrm{n}=10$ ) were analyzed along 3 consecutive days. UPLC-MS sample lists were set up as follows (sample type (technical replicates)): zero consisting of mobile phase analysis without injection (1); solvent blank (2); process blank (2); QC samples (5); spiked QC sample (1); randomized, and balanced samples (12) with 1 spiked QC sample analyzed every 4 samples; spiked QC sample (1); process blank (2); solvent blank (1).

The mass spectrometer was operated in positive ion mode with a probe capillary voltage of $2.5 \mathrm{kV}$ and a sampling cone voltage of $30.0 \mathrm{~V}$. The source and desolvation gas temperatures were set to 120 and $300{ }^{\circ} \mathrm{C}$, 554 respectively. The nitrogen gas desolvation flow rate was $600 \mathrm{~L} \mathrm{~h}^{-1}$, and the cone desolvation flow rate was 10 $555 \mathrm{~L} \mathrm{~h}$. The mass spectrometer was daily calibrated across the range of $m / z$ 50-1200 using a $0.5 \mathrm{mM}$ sodium 
557 a leucine encephalin ( $m / z 556.2771)$ reference spray (Waters cop, \#700008842) infused at $5 \mu$ min $^{-1}$, every 45 558 seconds. Data were acquired in MS continuum mode in the range of $m / z 50-1200$, and the scan time was set 559 to 0.5 seconds.

560 Principal component analysis (PCA) was conducted using MATLAB R2015a (The MathWorks, Natick, MA, USA) 561 with the PLS Toolbox version 8.1 (Eigenvector Research, Inc., Manson, WA, USA). PCA was used to track data 562 quality and to identify and remove outliers in the dataset. Two samples were identified as outliers by PCA, one 563 from WT and one from $\triangle A D H 5$ cells, and were not further considered for data analysis.

564 For UPLC-MS/MS experiments, the product ion mass spectra were acquired with collision cell voltages 565 between 10 and $30 \mathrm{~V}$, depending on the analyte. Ultra-high-purity argon ( $\geq 99.999 \%)$ was used as the collision 566 gas. Data acquisition and processing were carried out using MassLynx version 4.1 (Waters Corp., Milford, MA, 567 USA).

568 Chemical standards were prepared in ultrapure water and were analyzed under identical conditions as 569 samples to validate metabolite identities by chromatographic retention time and MS/MS fragmentation 570 pattern matching. Spiking experiments were also conducted with the authentic chemical standards on samples 571 to address retention time differences caused by matrix effects.

572 Two different normalization strategies were independently used for sample analysis: data were normalized by 573 number of viable cells or by protein content.

\section{Quantification and Statistical Analysis}

575 Prism software package (GraphPad Software 7) was used for statistical analysis with the level of significance 576 of 0.05 ( $95 \%$ confidence) and one-way ANOVA using the Tukey's algorithm for multiple comparisons. For mass 577 spectrometry data whisker plots and Mann-Whitney test was used to asses significance. The box and whiskers 578 plots are represented by a line in the box corresponding to the median; the edges are the 25th and 75th 579 percentiles and the whiskers extend to the most extreme values in data. Additional information about 580 statistical tests, sample number and P-values are described in figure legends. Unless otherwise stated, 581 experiments were done using technical replicates ( 2 or 3 wells per condition) and repeated the $\mathrm{n}$ times 
582 described in the figure legends with each symbol in a bar plot representing the average of the technical 583 replicates for a given biological sample.

\section{Data availability}

585 All data generated during this study are included in the published paper including source data for figure 2, 586 Extended data Fig. 1 and Extended data Fig. 5.

\section{Acknowledgements}

588 This work was supported by CONICET (PUE $201622920160100010 C O)$, FOCEM MERCOSUR (COF 03/11), 589 ANPyCT (PICT-PRH 2017-4668) and (PRH-PICT-2015-0022). LBP is a collaborative Group Leader between 590 IBioBA, MPI for Metabolism Research (Cologne, Germany) and MPI for Biophysical Chemistry (Göttingen, 591 Germany), from whom he receives support. B.S. acknowledges funding from the Deutsche 592 Forschungsgemeinschaft (SCHU 2494/3-1, SCHU 2494/7-1, SCHU 2494/10-1, SCHU 2494/11-1, SFB 829, KFO 593 286, KFO 329, GRK 2407) and the Deutsche Krebshilfe (70112899). IK acknowledges EMBO (ALTF 1029-2014). 594 LBP would like to acknowledge Prof. Jens Brüning and Prof. Thomas Wünderlich for providing support for 595 mouse breeding at MPI-MR. Also, to IBioBA staff for general support, to Gerry Crossan, Ricardo Biondi, 596 Alejandro Leroux and Carolina Perez Castro for the critical reading of the manuscript. CU, AM, HR, MM and AF 597 are CONICET fellows. MEM, MRM, MB and LBP are Research Staff Members from CONICET.

\section{Author contributions}

$599 \mathrm{CU}, \mathrm{AM}, \mathrm{MS}$ and HR carried out cellular experiments assisted by LBP. MR, KK and BS contributed with $C$. 600 elegans data generation and analysis. MRM and MEM designed the sample preparation protocol for 601 metabolite extraction, developed the UPLC-QTOF-MS-based method, and performed data analysis. MRM 602 conducted UPLC-MS/MS experiments. AF and MB synthesized S-hydroxymethyl-GSH. AV and IK processed 603 mouse blood samples. YW and RH measured blood FA. LBP conceived the work and wrote the paper. All 604 authors revised the manuscript. 
607 The authors declare no competing interests.

608 References

609 1. IARC Working Group on the Evaluation of Carcinogenic Risks to Humans., World Health Organization. \& International Agency for Research on Cancer. Formaldehyde, 2-Butoxyethanol and 1-tertButoxypropan-2-ol. (International Agency for Research on Cancer, 2006).

612 2. Shi, Y. et al. Histone demethylation mediated by the nuclear amine oxidase homolog LSD1. Cell 119, 941-953 (2004).

614 3. Burgos-Barragan, G. et al. Mammals divert endogenous genotoxic formaldehyde into one-carbon metabolism. Nature 548, 549-554 (2017).

4. Ma, T. H. \& Harris, M. M. Review of the genotoxicity of formaldehyde. Mutation Research/Reviews in Genetic Toxicology 196, 37-59 (1988).

5. Reingruber, H. \& Pontel, L. B. Formaldehyde metabolism and its impact on human health. Curr. Opin. Toxicol. 9, 28-34 (2018).

6. Wei, Y. et al. Simultaneous determination of seven endogenous aldehydes in human blood by headspace gas chromatography-mass spectrometry. J. Chromatogr. B Anal. Technol. Biomed. Life Sci.

7. Luo, W., Li, H., Zhang, Y. \& Ang, C. Y. Determination of formaldehyde in blood plasma by highperformance liquid chromatography with fluorescence detection. J. Chromatogr. B. Biomed. Sci. Appl. 753, 253-7 (2001).

8. Tan, S. L. W. et al. A Class of Environmental and Endogenous Toxins Induces BRCA2 Haploinsufficiency and Genome Instability. Cell 169, 1105-1118.e15 (2017).

628 9. Pontel, L. B. et al. Endogenous Formaldehyde Is a Hematopoietic Stem Cell Genotoxin and Metabolic 
630 10. Garaycoechea, J. I. et al. Alcohol and endogenous aldehydes damage chromosomes and mutate stem cells. Nature 553, 171-177 (2018).

11. Hira, A. et al. Variant ALDH2 is associated with accelerated progression of bone marrow failure in Japanese Fanconi anemia patients. Blood 122, 3206-3209 (2013).

12. Staab, C. A. et al. Reduction of S-nitrosoglutathione by alcohol dehydrogenase 3 is facilitated by substrate alcohols via direct cofactor recycling and leads to GSH-controlled formation of glutathione transferase inhibitors. Biochem. J. 413, 493-504 (2008).

13. Morgan, B. et al. Multiple glutathione disulfide removal pathways mediate cytosolic redox homeostasis. Nat. Chem. Biol. 9, 119-125 (2013).

14. Wu, G., Fang, Y.-Z., Yang, S., Lupton, J. R. \& Turner, N. D. Glutathione Metabolism and Its Implications for Health. J. Nutr. 134, 489-492 (2004).

15. Almusafri, F. et al. Clinical and molecular characterization of 6 children with glutamate-cysteine ligase deficiency causing hemolytic anemia. Blood Cells, Mol. Dis. 65, 73-77 (2017).

16. Roum, J. H., Buhl, R., McElvaney, N. G., Borok, Z. \& Crystal, R. G. Systemic deficiency of glutathione in cystic fibrosis. J. Appl. Physiol. 75, 2419-2424 (1993).

17. Knott, M. E. et al. Metabolic Footprinting of a Clear Cell Renal Cell Carcinoma in Vitro Model for Human

18. Bansal, A. \& Celeste Simon, M. Glutathione metabolism in cancer progression and treatment resistance. J. Cell Biol. 217, 2291-2298 (2018).

19. Ou, H. L. \& Schumacher, B. DNA damage responses and $\mathrm{p} 53$ in the aging process. Blood 131, 488-495 (2018).

20. Waypa, G. B. et al. Hypoxia triggers subcellular compartmental redox signaling in vascular smooth muscle cells. Circ. Res. 106, 526-535 (2010). 
1318-1319 (2019).

22. Romero-Aristizabal, C., Marks, D. S., Fontana, W. \& Apfeld, J. Regulated spatial organization and sensitivity of cytosolic protein oxidation in Caenorhabditis elegans. Nat. Commun. 5, (2014).

23. Gutscher, M. et al. Real-time imaging of the intracellular glutathione redox potential. Nat. Methods 5, $553-559$ (2008).

24. Wang, H., Park, H., Liu, J. \& Sternberg, P. W. An efficient genome editing strategy to generate putative null mutants in Caenorhabditis elegans using CRISPR/Cas9. G3 Genes, Genomes, Genet. 8, 3607-3616

25. Yang, W. \& Hekimi, S. A Mitochondrial Superoxide Signal Triggers Increased Longevity in Caenorhabditis elegans. PLoS Biol. 8, e1000556 (2010).

26. Zhang, Y. et al. Bone marrow injury induced via oxidative stress in mice by inhalation exposure to formaldehyde. PLoS One 8, (2013).

27. Kang, J. et al. Exposure to a combination of formaldehyde and DINP aggravated asthma-like pathology through oxidative stress and NF-KB activation. Toxicology 404-405, 49-58 (2018).

28. Ma, Q. Role of Nrf2 in Oxidative Stress and Toxicity. Thee Annu. Rev. Pharmacol. Toxicol. 53, 401-26 (2013).

29. Goto, M. et al. Alcohol dehydrogenase 3 contributes to the protection of liver from nonalcoholic steatohepatitis. Genes to Cells 20, 464-480 (2015).

30. Green, L. S. et al. Mechanism of inhibition for N6022, a first-in-class drug targeting S-nitrosoglutathione reductase. Biochemistry 51, 2157-2168 (2012).

31. Harris, I. S. et al. Glutathione and Thioredoxin Antioxidant Pathways Synergize to Drive Cancer Initiation and Progression. Cancer Cell 27, 211-222 (2015).

32. Harris, I. S. et al. Deubiquitinases Maintain Protein Homeostasis and Survival of Cancer Cells upon 
Cells upon Glutathione Depletion. Cell Metab. 1-16 (2019). doi:10.1016/j.cmet.2019.01.020

33. Ortega-Atienza, S., Rubis, B., McCarthy, C. \& Zhitkovich, A. Formaldehyde Is a Potent Proteotoxic Stressor Causing Rapid Heat Shock Transcription Factor 1 Activation and Lys48-Linked Polyubiquitination of Proteins. Am. J. Pathol. 186, 2857-2868 (2016).

34. Walter, D. et al. Exit from dormancy provokes DNA-damage-induced attrition in haematopoietic stem cells. Nature 520, 549-552 (2015).

35. Joenje, H., Arwert, F., Eriksson, A. W., De Koning, H. \& Oostra, A. B. Oxygen-dependence of chromosomal aberrations in Fanconi's anaemia. Nature 290, 142-143 (1981).

36. Ponte, F. et al. Improvement of genetic stability in lymphocytes from Fanconi anemia patients through the combined effect of $\alpha$-lipoic acid and N-acetylcysteine. Orphanet J. Rare Dis. 7, 28 (2012).

37. Zhang, Q. S. et al. Metformin improves defective hematopoiesis and delays tumor formation in Fanconi anemia mice. Blood 128, 2774-2784 (2016).

38. Bunz, F. et al. Requirement for $\mathrm{p} 53$ and $\mathrm{p} 21$ to sustain $\mathrm{G} 2$ arrest after DNA damage. Science (80-. ). 282, 1497-1501 (1998).

39. Van Den Pol, A. N. et al. Neuromedin B and Gastrin-releasing peptide excite arcuate nucleus neuropeptide y neurons in a novel transgenic mouse expressing strong renilla green fluorescent protein in NPY neurons. J. Neurosci. 29, 4622-4639 (2009).

40. Brenner, S. THE GENETICS OF CAENORHABDITIS ELEGANS. Genetics 77, (1974).

41. Sarov, M. et al. A genome-scale resource for in vivo tag-based protein function exploration in C. elegans. Cell 150, 855-866 (2012).

42. Rieckher, M. \& Tavernarakis, N. Generation of Caenorhabditis elegans Transgenic Animals by DNA Microinjection. BIO-PROTOCOL 7, (2017).

43. Kim, E., Sun, L., Gabel, C. V. \& Fang-Yen, C. Long-Term Imaging of Caenorhabditis elegans Using Nanoparticle-Mediated Immobilization. PLoS One 8, e53419 (2013). 
702 44. Paix, A., Folkmann, A. \& Seydoux, G. Precision genome editing using CRISPR-Cas9 and linear repair templates in C. elegans. Methods 121-122, 86-93 (2017).

45. Arribere, J. A. et al. Efficient marker-free recovery of custom genetic modifications with CRISPR/Cas9 in caenorhabditis elegans. Genetics 198, 837-846 (2014).

46. Schneider, C. A., Rasband, W. S. \& Eliceiri, K. W. NIH Image to ImageJ: 25 years of image analysis. Nature Methods 9, 671-675 (2012).

47. Dereeper, A. et al. Phylogeny.fr: robust phylogenetic analysis for the non-specialist. Nucleic Acids Res. 36, (2008).

48. Su, T., Wei, Y. \& He, R. Q. Assay of brain endogenous formaldehyde with 2,4-dinitrophenylhydrazine through UV-HPLC. Prog. Biochem. Biophys. 38, 1171-1177 (2011). Reaction Conditions in the Reaction of Formaldehyde with an Alpha-Mercapto Amide. Heterocycles 48, 1307 (1998).

Fig. titles and legends.

\section{Fig. 1. ADH5 prevents formaldehyde toxicity in human cancer cells}

a. Scheme showing formaldehyde (FA) metabolism, glutathione (GSH) de novo synthesis and the central role

719 of ADH5 (alcohol dehydrogenase 5). GCL: glutamate cysteine ligase; GS: glutathione synthetase; ROS: Reactive 720 Oxygen Species.

721 b. FA in blood of 6-month old mice determined by high-performance liquid chromatography with ultraviolet 722 detection (UV-HPLC) (mean \pm s.e.m., $n=7$ (males), $n=7$ (females), $n=14$ (both sexes).

723 c. Representative images of 3D-sphere formation for HCT116 Wild type (WT), $\triangle A D H 5$ and $\triangle A D H 5 / p A D H 5$ cells 724 (scale bar $0.5 \mathrm{~mm}$ ). 
725 d. Resazurin-based viability assay expressed as \% of fluorescence relative to untreated cells. Each point 726 represents the mean \pm s.e.m. of 6 independent experiments done by triplicate. Asterisks represent the 727 statistical significance according to one-way ANOVA for multiple comparison using a Tukey-corrected test 728 between Wild type and $\triangle A D H 5$ cells.

729 e. Apoptosis determined by Annexin $\mathrm{V}$ detection in cells exposed to FA over $24 \mathrm{~h}$ at the concentrations 730 indicated in the figure (mean \pm s.e.m., $n=5$, unpaired t-test).

731 f. Cell cycle analysis of Wild type and $\triangle A D H 5$ HCT116 cells exposed to 60 and $150 \mu \mathrm{M}$ FA over $24 \mathrm{~h}$ (mean \pm 732 s.e.m., $n=4)$.

\section{Fig. 2. Formaldehyde triggers a p53 response in absence of $A D H 5$}

734 a. Resazurin-based viability assay expressed as \% of fluorescence relative to untreated cells in Wild Type (WT), $735 \triangle A D H 5, \triangle P 53$ and $\triangle P 53 \triangle A D H 5$ cells exposed to increasing concentrations of formaldehyde (FA) (mean \pm 736 s.e.m., $\mathrm{n}=8)$.

737 b. Colony survival assay prepared seeding 600 cells in 6-well plates in presence of the indicated concentration 738 of formaldehyde (FA). Colonies were stained and quantified after 10 days (mean \pm s.e.m., $n=4$, one-way 739 ANOVA using Tukey multiple comparison test).

740 c. Western blot showing the induction of $\mathrm{p}-\mathrm{p} 53$ and $\gamma-\mathrm{H} 2 \mathrm{AX}$ after $48 \mathrm{~h}$ of exposure to the indicated 741 concentrations of FA or $24 \mathrm{~h}$ of exposure to the genotoxic compounds cisplatin $(4 \mu \mathrm{M})$, hydroxyurea (HU, 1 $742 \mathrm{mM})$ and mitomycin C (MMC, $1.5 \mu \mathrm{M})$.

743 d. Quantitation of p-p53 and $\gamma$-H2AX western blots using ImageJ (p-p53: FA 0, 60, 150 and cisplatin n=5; HU $744 n=4, M M C n=3 . \gamma$-H2AX: FA 0, 60, 150, cisplatin and HU $n=4 ; M M C n=3$; mean \pm s.e.m., unpaired t-test 745 comparing against the same cell line untreated)

746 e. Quantitation of metaphase scoring (mean \pm s.e.m., $n=49$, one-way ANOVA, Tuckey's multiple comparison 747 test) denoting the induction of chromosome damage by MMC $(1.5 \mu \mathrm{M})$ but not by FA $(150 \mu \mathrm{M})$.

748 f. Representative images of Wild Type and $\triangle A D H 5$ cells exposed to $150 \mu \mathrm{M}$ FA and to $1.5 \mu \mathrm{M}$ MMC (scale bar $7491 \mu \mathrm{m})$. 
Fig. 3. Oxidative stress underlies formaldehyde cytotoxicity

751 a. Oxidative stress determination by $2^{\prime}, 7^{\prime}$-dichlorodihydrofluorescein diacetate (HFDCDA) in Wild type, $752 \triangle A D H 5$, and complemented $\triangle A D H 5$ ( $\triangle A D H 5 / \mathrm{pADH5}) \mathrm{HCT} 116$ cells upon $48 \mathrm{~h}$ exposure to formaldehyde (FA).

753 Data is represented as the \% of fluorescence detected in the untreated samples from the same cell line (mean $754 \pm$ s.e.m., $n=3$, one-way ANOVA, Tuckey's multiple comparison test).

755 b. Representative plots of oxidative stress determination as described in a.

756 c. Flow cytometry representative plots obtained from Wild type and $\triangle A D H 5$ cells harboring the cytoplasmic757 roGFP reporter. Cells were excited at $\lambda=405$ or $\lambda=488 \mathrm{~nm}$ and emission recorded at $\lambda=510 \mathrm{~nm}$.

758 d. Quantitation of experiments shown in d (mean \pm s.e.m., $n=3$, one-way ANOVA, Tuckey's multiple 759 comparison test).

760 e. Resazurin-based viability at 0,60 and $150 \mu \mathrm{M}$ FA denoting the rescue of cell viability by N-acetylcysteine 761 (NAC, $500 \mu \mathrm{M})$, Trolox (1 mM) and glutathione monoethyl ester (GSH-MEE, $1 \mathrm{mM}$ ). L-buthionine-sulfoximine 762 (L-BSO) was used at $100 \mu \mathrm{M}$. The data represent the mean \pm s.e.m. of 4 experiments done in triplicate (one763 way ANOVA, Tuckey's multiple comparison test).

764 f. Representative images of the 3D-tumour spheroid formation phenotype in presence of the indicated FA 765 concentration and the combination of the antioxidants described in e (scale bar $0.5 \mathrm{~mm}$ ).

766 g. Quantitation of 3D-sphere area from 10 formed spheres at day 5 after seeding (mean \pm s.e.m., one-way 767 ANOVA, Tuckey's multiple comparison test).

768 f. Quantitation of sphere formation phenotype at day 5 after seeding 2000 cell/well of WT or $\triangle A D H 5$ cells in 769 presence of FA $(150 \mu \mathrm{M}) ; \mathrm{FA}$ and NAC $(500 \mu \mathrm{M})$; or FA, NAC and L-BSO $(100 \mu \mathrm{M})$. The plots correspond to a 770 part of the whole representation (WT + FA, $\mathrm{n}=30 ; \triangle A D H 5+\mathrm{FA}, \mathrm{n}=28 ; \mathrm{WT}+\mathrm{FA}+\mathrm{NAC}, \mathrm{n}=29 ; \triangle A D H 5+\mathrm{FA}+$ 771 NAC, $n=29 ; W T+F A+N A C+L-B S O, n=27 ; \triangle A D H 5+F A+N A C+L-B S O, n=28)$. 
777 a. Resazurin-based viability assay in Wild type (WT) and $\triangle A D H 5$ Nalm6 cells in presence of different concentrations of formaldehyde (FA) with or without $50 \mu \mathrm{M} \mathrm{L-buthionine-sulfoximine} \mathrm{(L-BSO)} \mathrm{(mean} \pm$ s.e.m., $779 \mathrm{n}=6)$.

780 b. HCT116 3D-spheroid formation in presence of $100 \mu \mathrm{M} \mathrm{L-BSO}$ and the indicated concentrations of FA. 781 Pictures were taken 5 days after seeding cells on agarose-coated plates (scale bar $0.5 \mathrm{~mm}$ ).

782 c. Resazurin-based viability assay performed with Wild type, $\triangle A D H 5, \triangle G C L M$ and $\triangle A D H 5 \triangle G C L M$ cells in 783 response to increasing concentrations of FA (mean \pm s.e.m., $n=5$, asterisks represent the statistical significance 784 according to one-way ANOVA for multiple comparison using a Tukey-corrected test between Wild type and $785 \Delta G C L M)$

786 d. Representative images of HCT116 3D-spheroid formation for the same cell lines described in (C). Pictures 787 were taken at day 5 after seeding (scale bar $0.5 \mathrm{~mm}$ ).

788 e. Colony survival assay prepared seeding 600 of WT, $\triangle A D H 5, \triangle G C L M$ and $\triangle G C L M \triangle A D H 5$ cells in 6-well plates 789 in presence of the indicated concentration of FA (mean \pm s.e.m., $n=5$, one-way ANOVA using a Tukey's multiple 790 comparison test).

791 f. Representative images of the colony survival assay quantified in e.

\section{Fig. 5. Endogenous formaldehyde reacts with GSH altering the GSH:GSSG ratio}

793 a. Scheme showing the spontaneous reaction between formaldehyde (FA) and glutathione (GSH) yielding S794 hydroxymethylglutathione (HSMGSH).

b. Extracted ion chromatograms for [HSMGSH $+\mathrm{H}]+$ ion at $\mathrm{m} / \mathrm{z} 338.1022 \pm 0.0500$ generated from a nonspiked Wild type (WT) sample (green, left axis), a $20 \mu \mathrm{M}$ spiked WT sample (black dotted line, right axis), and 797 a $20 \mu \mathrm{M}$ HSMGSH standard solution (blue, left axis).

798 c. Product ion mass spectra of $[\mathrm{HSMGSH}+\mathrm{H}]^{+}$precursor ion for a WT sample (green), and for a $20 \mu \mathrm{M}$ HSMGSH 799 standard solution (blue), using a collision cell voltage of $10 \mathrm{~V}$. 
800 d. Box and whiskers plot for GSH content in WT and $\triangle A D H 5$ cells calculated as normalized chromatographic 801 peak areas relative to the number of viable cells ( $n=9$, Mann-Whitney test, $\left.{ }^{* * *} \mathrm{P}<0.0001\right)$. The box and 802 whiskers plots are represented by a line in the box corresponding to the median; the edges are the 25th and 803 75th percentiles and the whiskers extend to the most extreme values in data.

804 e. Left: Box and whiskers plot for HSMGSH content relative to GSH in WT and $\triangle A D H 5$ cells ( $n=9$, Mann-Whitney 805 test). Right: Net HSMGSH content in WT and $\triangle A D H 5$ cells calculated as normalized peak areas relative to the 806 number of viable cells ( $n=9$, Mann-Whitney test).

807 f. Box and whiskers plot for total GSH (GSH disulfide (GSSG) plus GSH) content in WT and $\triangle A D H 5$ cells 808 calculated as normalized peak areas relative to the number of viable cells ( $n=9$, Mann-Whitney test).

809 g. Bar plots for GSH content in WT ( $\mathrm{n}=17), \triangle A D H 5(\mathrm{n}=15), \triangle A D H 5 / \mathrm{pADH5}(\mathrm{n}=8), \triangle G C L M(\mathrm{n}=4)$ and $\triangle A D H 5$ $810 \Delta G C L M(n=4)$ cells, and in WT $(n=7)$ and $\triangle A D H 5(n=7)$ cells exposed to $100 \mu M$ L-BSO for $48 \mathrm{~h}$. Every dot is the 811 percentage of fluorescence intensity in a single well relative to the average fluorescence of WT samples run 812 the same day and corrected for viability determined using resazurin (mean \pm s.e.m., unpaired t-test).

813 h. Box and whiskers plot for GSSG content in WT and $\triangle A D H 5$ cells calculated relative to the number of viable 814 cells ( $n=9$, Mann-Whitney test).

815 i. Box and whiskers plot for GSH:GSSG ratio in WT and $\triangle A D H 5$ cells ( $n=9$, Mann-Whitney test).

816 j. Flow cytometry representative plots from WT and $\triangle A D H 5$ cells harboring the cytosolic Grx1-roGFP2 817 reporter. Data was recorded $48 \mathrm{~h}$ post-FA exposure.

818 k. Quantitation of oxidized Grx1-GFP2 (OxD (Grx1-roGFP2)) sensor from plots depicted in (J) (mean \pm s.e.m., $819 \mathrm{n}=4$, unpaired $\mathrm{t}$-test).

820 Fig. 6. The $A D H 5$ ortholog in C. elegans and GSH synthesis in Fanconi Anemia-deficient cells

821 a. Various developmental stages of a $C$. elegans transgenic line expressing Ex[padh-5ADH-5::GFP; $p_{\text {myo- }}$ $822{ }_{2}$ tdTomato]. White arrows point to nuclei. Scale bars represent $50 \mu \mathrm{m}$. Gray inlays show the corresponding 823 DIC image. (i) Adult stage boxes refer to ii and iii. (ii) Head area with focus on the intestine of the adult depicted 
824 in i, recorded with 40x magnification. (iii) Tail area with focus on the cuticle of the animal shown in i, recorded 825 with 40x magnification. (iv) L4 stage. (v) L3 stage. (vi) Late embryo.

826 b. Scheme depicting the protocol used to treat C. elegans with formaldehyde (FA) and N-acetylcysteine (NAC).

827 c. Survival of L1-staged Wild type (N2) and adh-5 mutant upon exposure to the indicated FA concentrations 828 and $10 \mu \mathrm{M} N A C$ measured directly after treatment (mean \pm S.D., $n=3$ ).

829 d. Development profile of surviving animals $72 \mathrm{~h}$ after FA exposure (mean \pm S.D., $n=3$ ).

830 e. Scheme depicting the protocol used to treat $C$. elegans with FA and paraquat (PQ).

831 f. Development profile of surviving animals $72 \mathrm{~h}$ upon FA and $P Q$ exposure (mean \pm S.D., $n=3$ ).

832 g. Resazurin-based viability assay for Nalm6 cells exposed to increasing concentrations of FA and $50 \mu \mathrm{M} \mathrm{L-}$ 833 buthionine-sulfoximine (L-BSO), denoting the protection against FA by glutathione (GSH) biosynthesis (mean $834 \pm$ s.e.m., $\mathrm{n}=6$, asterisks represent one-way ANOVA for multiple comparison using a Tukey-corrected test 835 between $\triangle F A N C B$ and $\triangle F A N C B+\mathrm{L}-\mathrm{BSO} 50 \mu \mathrm{M})$.

836 h. Resazurin-based viability assay for Nalm6 cells exposed to increasing concentrations of L-BSO (mean \pm 837 s.e.m., $n=6$, asterisks represent the statistical significance according to one-way ANOVA for multiple 838 comparison using a Tukey-corrected test between Wild type (WT) and $\triangle F A N C B$ cells).

839 i. Model for FA metabolism and the crosstalk with GSH metabolism highlighting the formation of HSMGSH 840 adducts and the metabolization through ADH5. GSH supply by ADH5 limits oxidative stress and sustains the 841 balance between GSH and GSH disulfide (GSSG).

\section{Supplemental Information titles and legends}

\section{Extended Data Fig. 1, $\triangle A D H 5$ cell generation and P53 response to formaldehyde}

844 a. Western blot analysis of ADH5 expression in clones edited by CRISPR/Cas9. b. ADH5 gene showing the exon 845 targeted by CRISPR/Cas9 and the genetic modifications of the $\triangle A D H 5$ clone used in this work. c. Left: 846 Representative flow cytometry plot for Annexin $V$ determination in $\triangle A D H 5$ cells untreated or exposed to 150 $847 \mu \mathrm{M}$ formaldehyde (FA). Right: Gating strategy for determining apoptotic cells. d. Resazurin-based viability 848 assay for Nalm6 cells exposed to increasing concentrations of FA (mean \pm s.e.m., $n=6$, asterisks represent the 849 statistical significance according to one-way ANOVA for multiple comparison using a Tukey-corrected test 
between WT and $\triangle A D H 5)$. e. Western blot analysis of ADH5 expression in $\triangle P 53$ clones edited by CRISPR/Cas9.

f. $A D H 5$ gene showing the exon targeted and the genetic modifications of the $\triangle P 53 \triangle A D H 5$ clone used in this

work. g. Western blot against p21 and p53. Loading control $\beta$-actin. h. Quantitation of western blots against p21 (left) and p53 (right) (s.e.m., n=3).

\section{Extended Data Fig. 2, GSH biosynthesis inactivation}

a. Resazurin-based viability assay for HCT116 (left) and Nalm6 (right) Wild type (WT) and $\triangle A D H 5$ cells at 100 and $50 \mu \mathrm{M}$ L-buthionine-sulfoximine (L-BSO), respectively (s.e.m., $\mathrm{n}=5$ ). b. Western blot analysis of GCLM expression in clones edited by CRISPR/Cas9. c. $A D H 5$ gene showing the exon targeted by CRISPR/Cas9 and the genetic modifications of the $\triangle A D H 5$ clone on which GCLM was inactivated. d. GCLM gene showing the exon targeted by CRISPR/Cas9 and the genetic modifications of the $\triangle G C L M$ clones used in this work.

\section{Extended Data Fig. 3, S-hydroxymethylglutathione synthesis}

a. Extracted ion chromatograms for $[\mathrm{GSH}+\mathrm{H}]^{+}$ion at $\mathrm{m} / \mathrm{z} 308.0916$ generated from a $10.4 \mu \mathrm{M}$ glutathione

(GSH) standard solution before reaction ( $\mathrm{t}_{0}$ : green dash line) and after $48 \mathrm{~h}$ of reaction ( $\mathrm{t}_{48}$ : green solid line); and for [S-hydroxymethylglutathione $(\mathrm{HSMGSH})+\mathrm{H}]^{+}$ion at $\mathrm{m} / \mathrm{z} 338.1022$ generated from a $10.4 \mu \mathrm{M}$ GSH standard solution before reaction ( $t_{0}$ : blue dash line) and after $48 \mathrm{~h}$ reaction ( $t_{48}$ : blue solid line). b. Mass spectrum for the solvent at $t_{0}$, with no signals detected at $m / z$ 308.0916 or $m / z$ 338.1022. c. Mass spectrum for a GSH standard solution at $t_{0}$, with no signal detected at $m / z$ 338.1022. d. Mass spectrum for the reaction mixture at $t_{48}$.

\section{Extended Data Fig. 4, in vivo detection of S-hydroxymethylglutathione}

872 a. Mass spectrum for [S-hydroxymethylglutathione (HSMGSH) $+\mathrm{H}]^{+}$ion at $m / z 338.1022$ in a Wild type (WT) 873 sample (green), and its simulated isotopic pattern (blue). b. Extracted ion chromatograms for [Glutathione $874(\mathrm{GSH})+\mathrm{H}]^{+}$ion at $\mathrm{m} / \mathrm{z} 308.0916 \pm 0.0500$ generated from a non-spiked QC sample (green), a $43 \mu \mathrm{M}$ spiked QC 875 sample (red), and a $14.3 \mu \mathrm{M}$ GSH standard solution (blue). c. Mass spectrum for [GSH + H] $]^{+}$ion at $m / z 308.0916$ 
876 obtained from a QC sample (green), and its simulated isotopic pattern (blue). d. Product ion mass spectrum 877 for $[\mathrm{GSH}+\mathrm{H}]^{+}$precursor ion obtained from a QC sample (green), and a $14.3 \mu \mathrm{M} \mathrm{GSH}$ standard solution (blue), 878 using a collision cell voltage of $10 \mathrm{~V}$. e. Extracted ion chromatograms for [GSH disulfide(GSSG) $+\mathrm{H}]^{+}$ion at $\mathrm{m} / \mathrm{z}$ $879613.1598 \pm 0.0500$ generated from a non-spiked QC sample (green), a $15.5 \mu \mathrm{M}$ spiked QC sample (red), and a $88015.5 \mu \mathrm{M}$ GSSG standard solution (blue). f. Mass spectrum for [GSSG $+\mathrm{H}]^{+}$ion at $m / z 613.1598$ obtained from 881 a QC sample (green), and its simulated isotopic pattern (blue). g. Product ion mass spectrum for [GSSG $+\mathrm{H}]^{+}$ 882 precursor ion obtained from a QC sample (green), and a $15.5 \mu \mathrm{M}$ GSSG standard solution (blue) using a 883 collision cell voltage of $20 \mathrm{~V}$. h. Extracted ion chromatograms for [GSSG $+2 \mathrm{H}]^{2+}$ ion at $\mathrm{m} / \mathrm{z} 307.0838 \pm 0.0500$ 884 generated from a non-spiked QC sample (green), a $15.5 \mu \mathrm{M}$ spiked QC sample (red), and a $15.5 \mu \mathrm{M}$ GSSG 885 standard solution (blue). i. Mass spectrum for [GSSG $+2 \mathrm{H}]^{2+}$ ion at $m / z 307.0838$ obtained from a QC sample 886 (green), and its simulated isotopic pattern (blue). j. Mass spectrum for [GSSG $+\mathrm{H}]^{+}$precursor ion obtained 887 from a 15.5 MM GSSG standard solution (blue).

Extended Data Fig. 5, ADH5 is conserved and prevents FA toxicity in C. elegans, related to Figure 6

890 a. Phylogenetic analysis of $A D H 5$-homolog genes in eukaryote highlighting the ortholog gene 891 (gi_71997431/H24K24.3) found in C. elegans.

892 b. Survival of L1-staged Wild type (N2) and $a d h-5$ mutant upon exposure to the indicated FA concentrations 893 and $10 \mu \mathrm{M} \mathrm{NAC}$ measured $0,24,48$ and $72 \mathrm{~h}$ after treatment (mean \pm S.D., $\mathrm{n}=3$ ).

894 c. Development profile of surviving animals $48 \mathrm{~h}$ after FA exposure (mean \pm S.D., $n=3$ ).

896 Source data:

897 Source Data Fig. 2: Uncropped images for western blots from Fig. 2

898 Source Data Extended Data Fig. 1: Uncropped images for western blots from Extended Data Fig. 1

899 Source Data Extended Data Fig. 5: List of sequences used for phylogenetic analysis. 


\section{Figure 1}

a

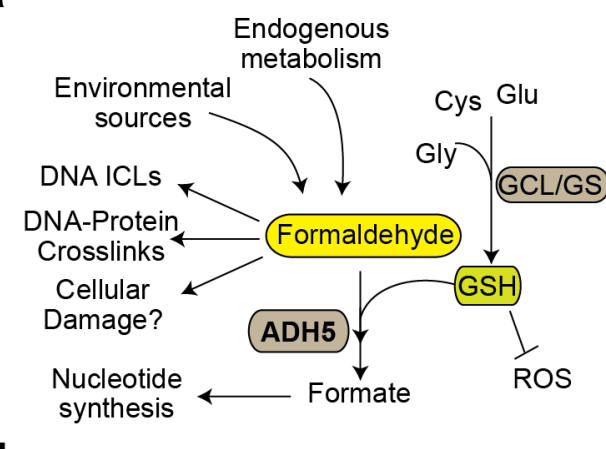

d

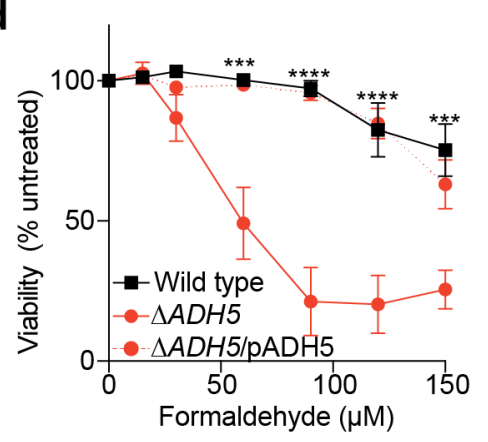

b

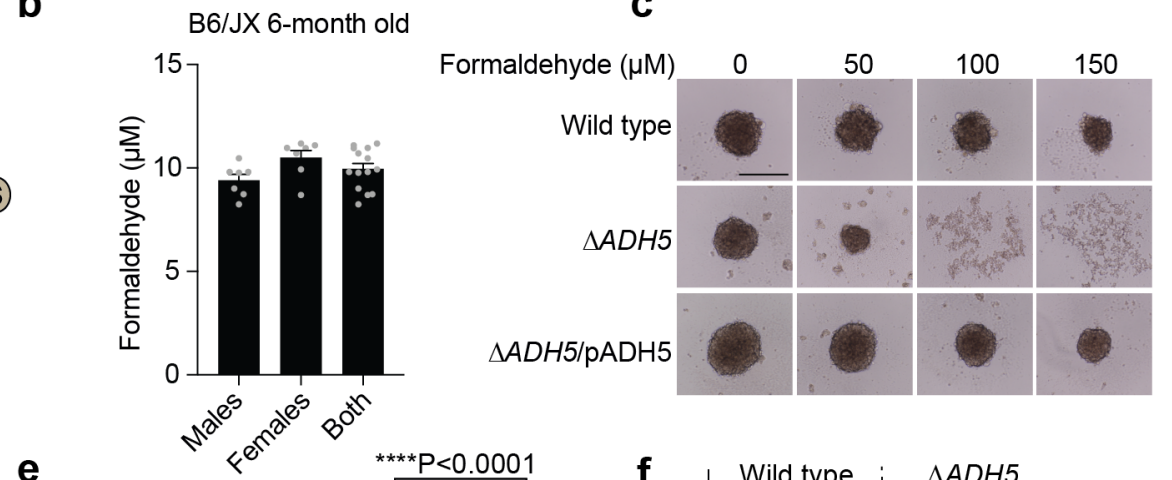

Formaldehyde $(\mu \mathrm{M})$

C
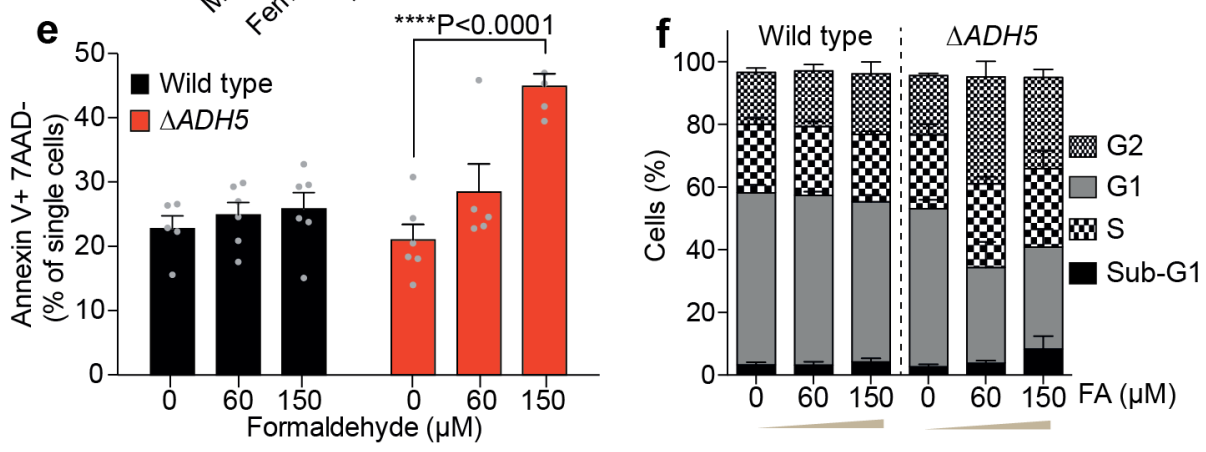


\section{Figure 2}

a

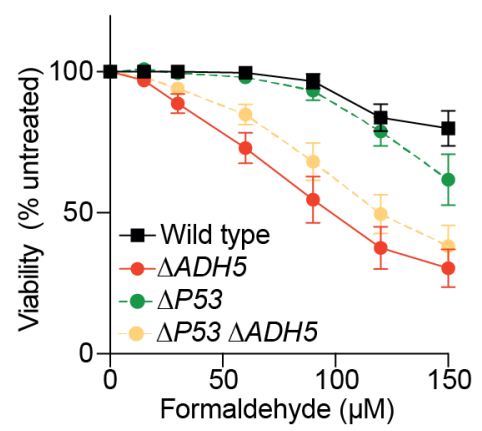

b

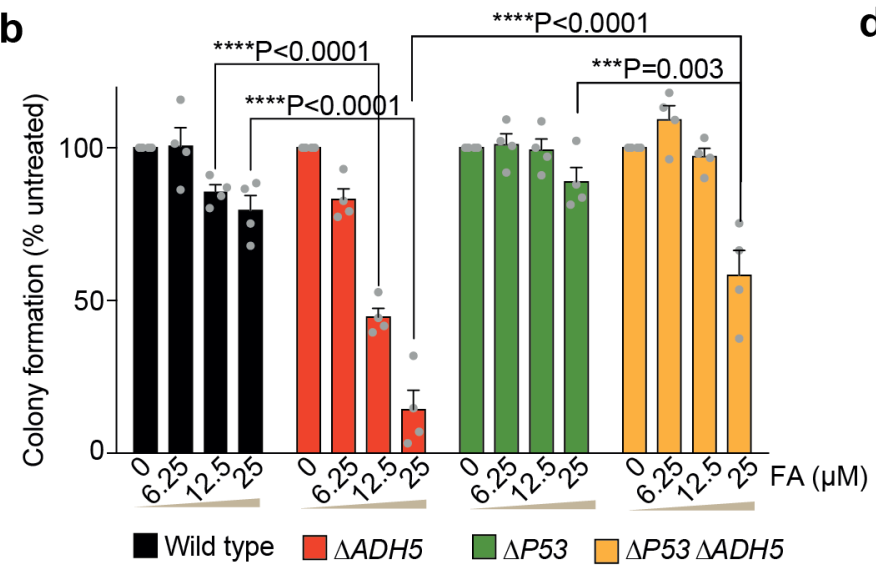

C

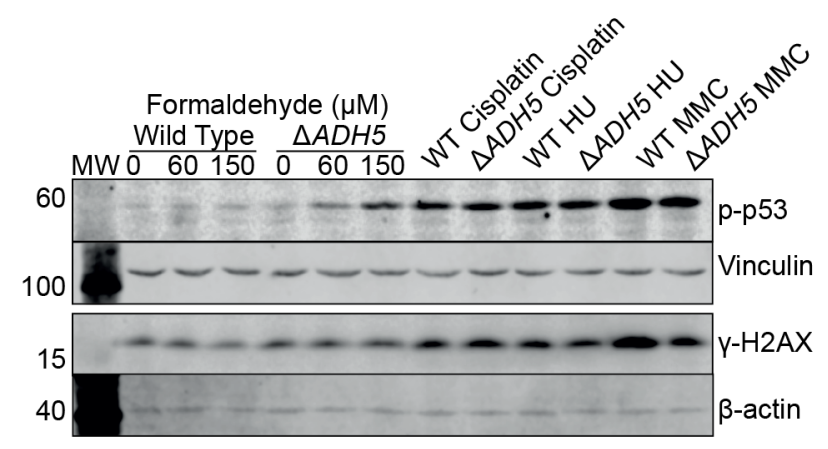

d

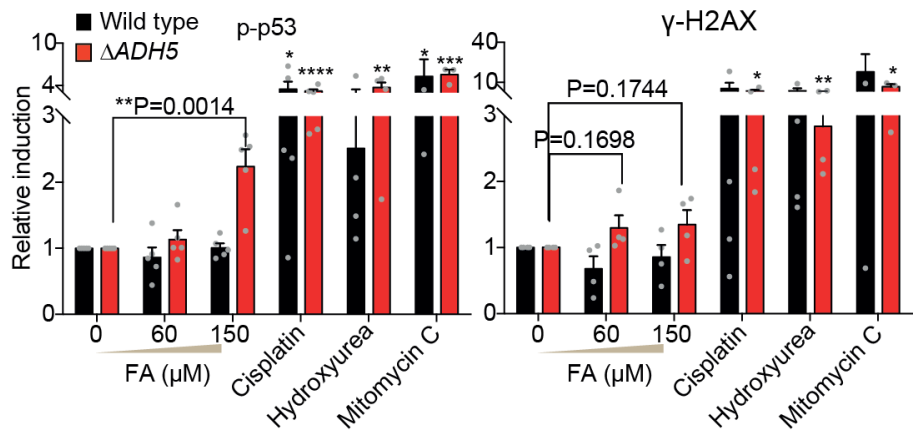

e

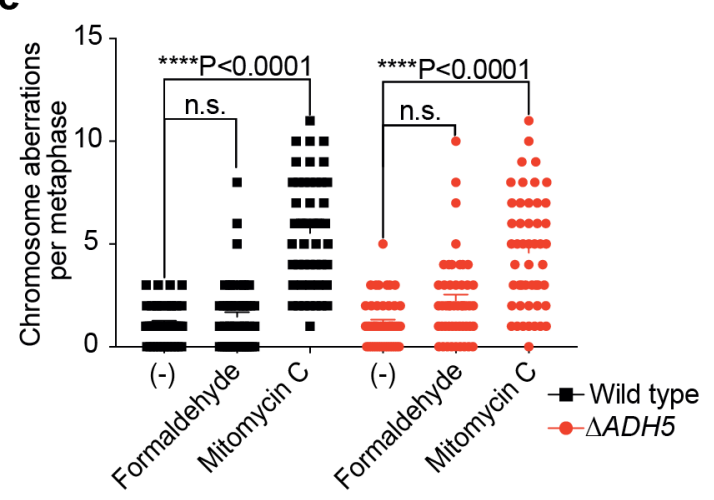

$\mathbf{f}$

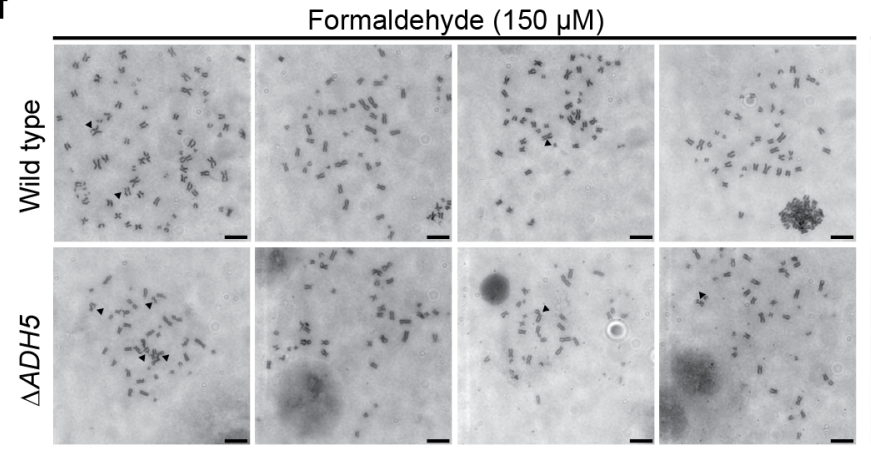

$\operatorname{MMC}(1.5 \mu \mathrm{M})$

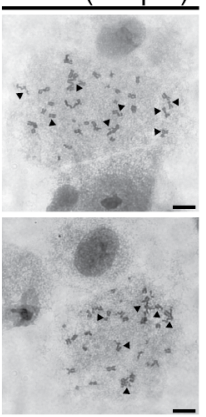




\section{Figure 3}
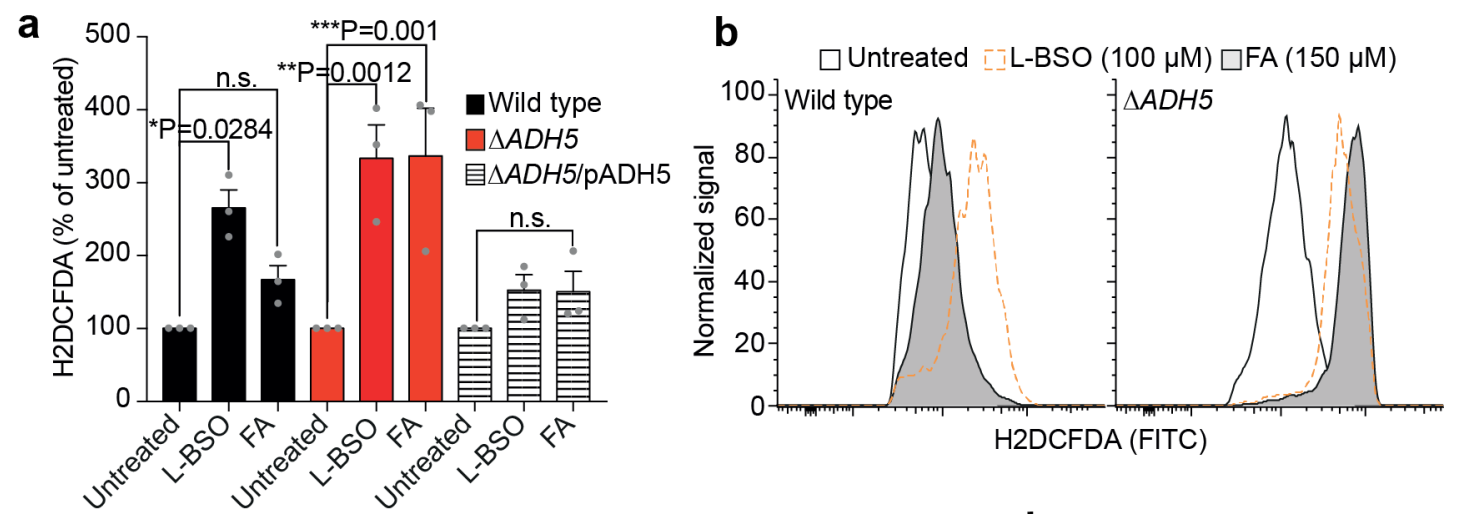

C

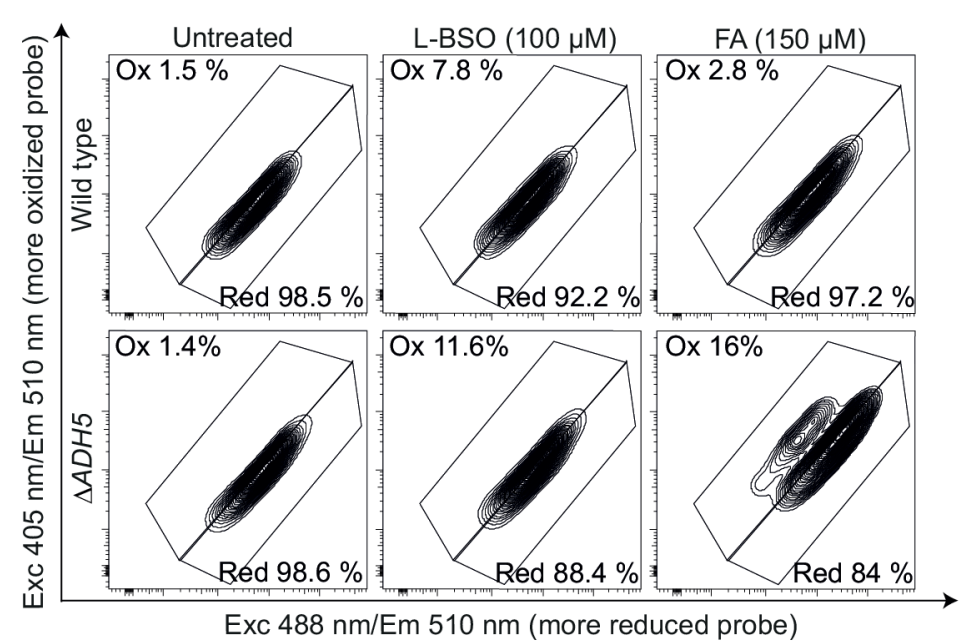

d
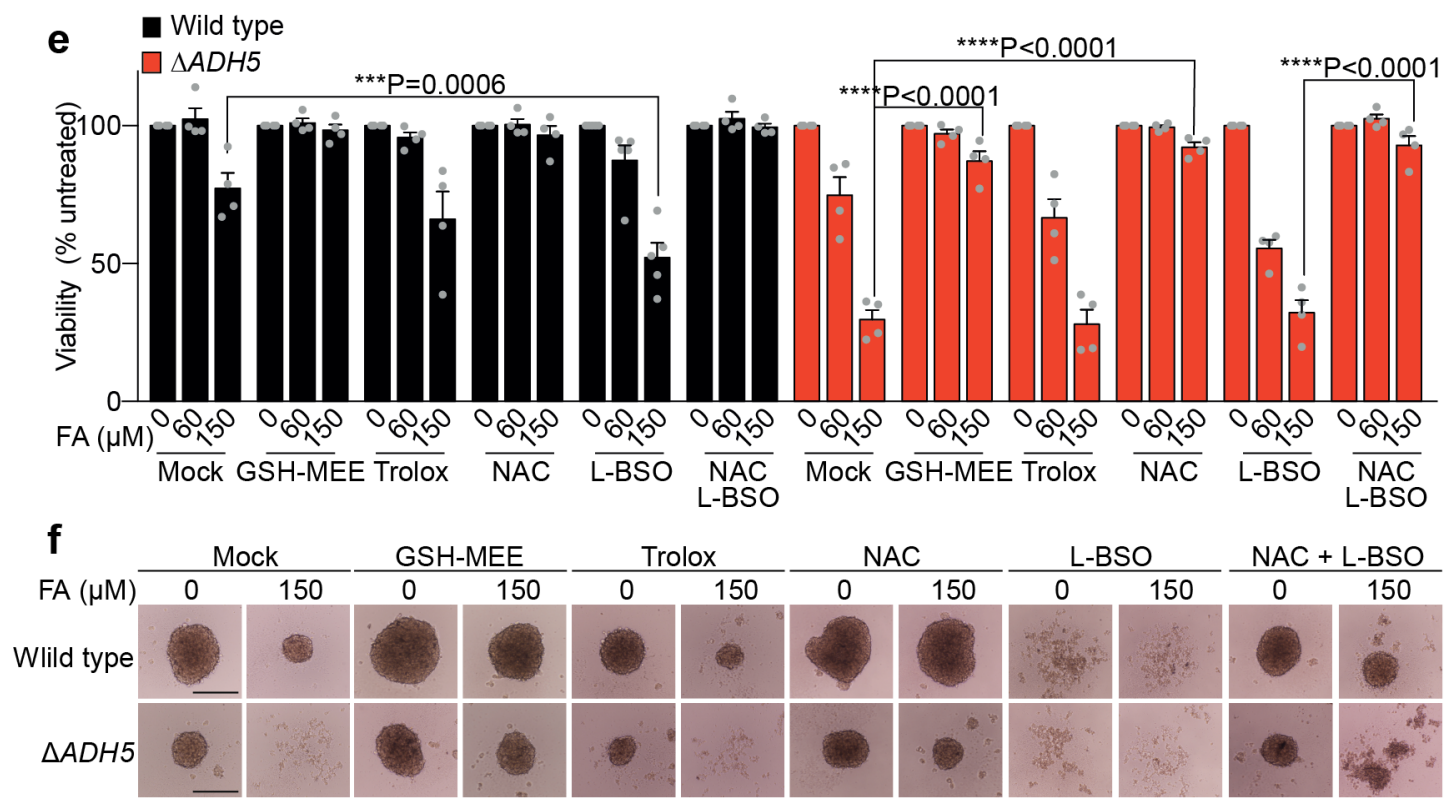

g

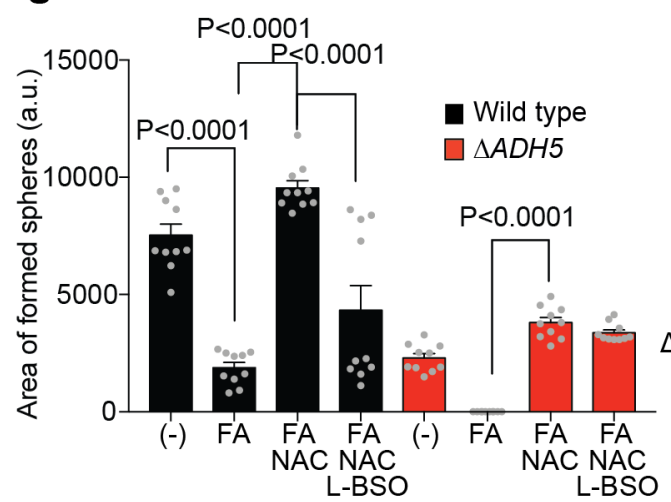

h

$\frac{\mathrm{FA}}{76.7 \% 00000} \mathrm{FA}+\mathrm{NAC} \quad \mathrm{FA}+\mathrm{NAC}+\mathrm{L}-\mathrm{BSO}$ $76.7 \% 0000001100 \%$ D00000 '96.3\%D00000

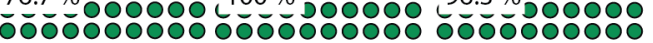
0000000000 0000000000 0000000000

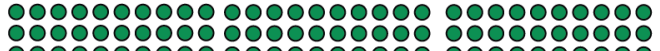
WT o 更 000000000000000000000000000000 $0 \%$ O

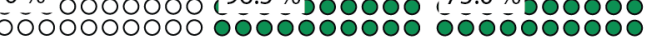
000000000000000000000000000000 000000000000000000000000000000 000000000 0000000000 0000000000 0000000000 0000000000000000000 00000000000000000000000000000 O000000000 0000000000 0000000000 000000000000000000000000000000 $\square$ Sphere $\square$ No Sphere 


\section{Figure 4}

a

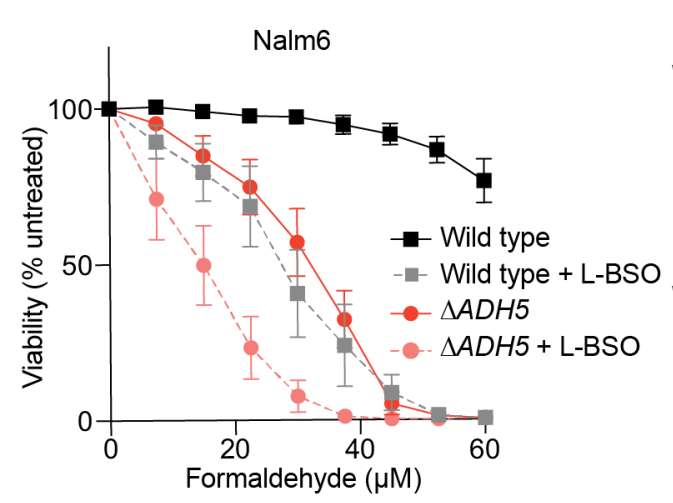

d

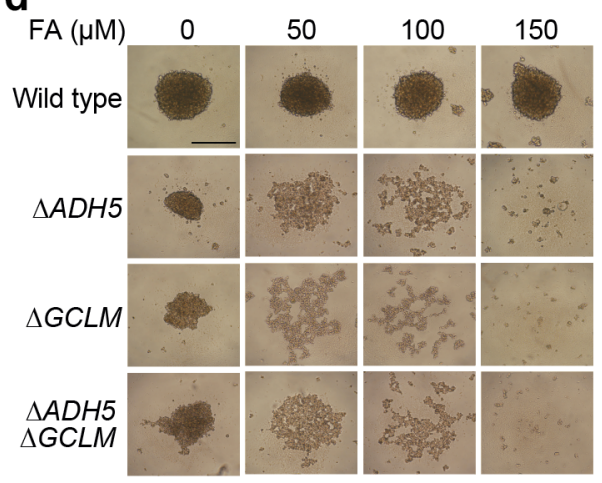

b

e
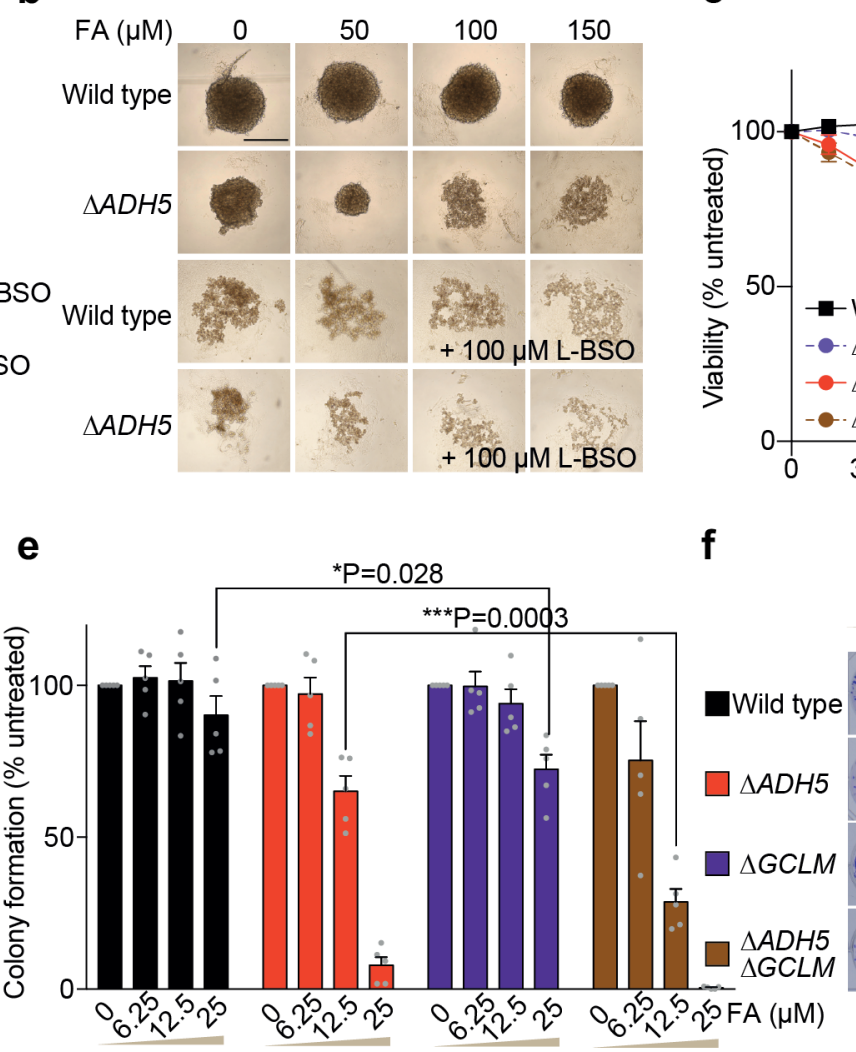

HCT116

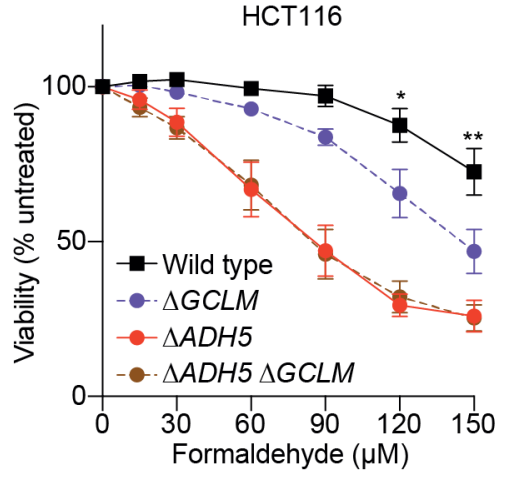

Formaldehyde $(\mu \mathrm{M})$

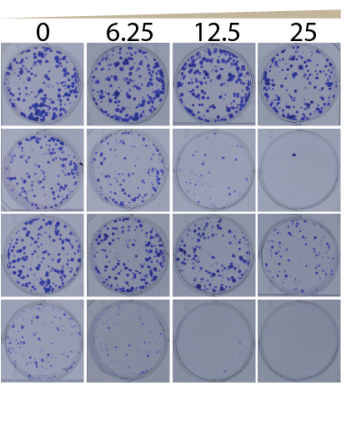




\section{Figure 5}

a<smiles>C=C(C)CCC(=O)NC(CC)C(=O)NCC(=O)C(C)C</smiles>

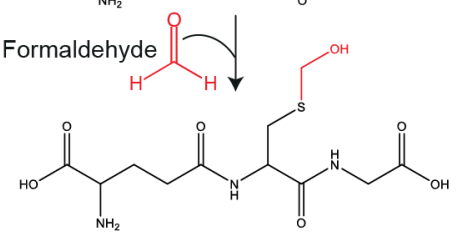

S-hydroxymethylglutathione (HSMGSH)

d

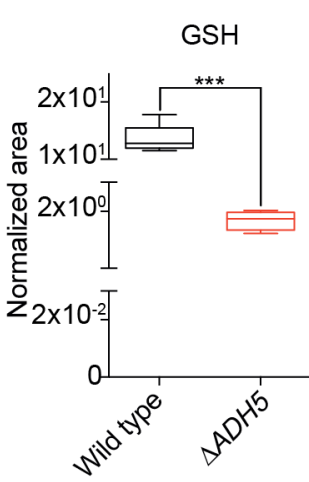

b

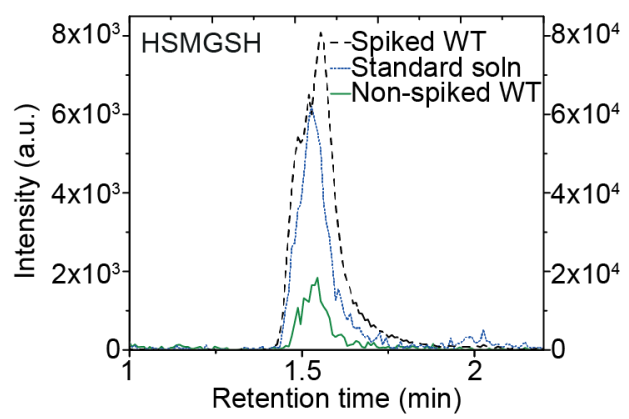

C
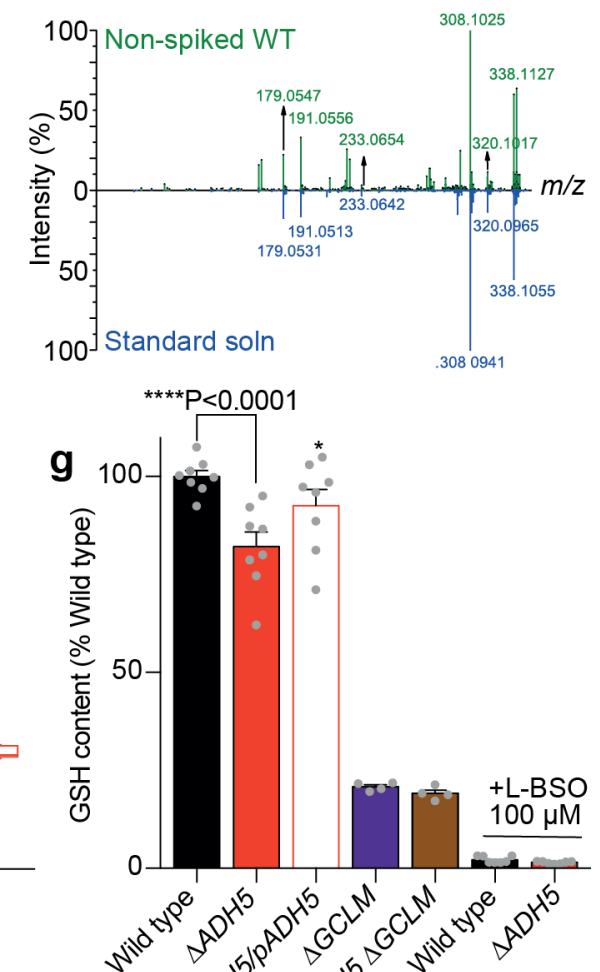

h

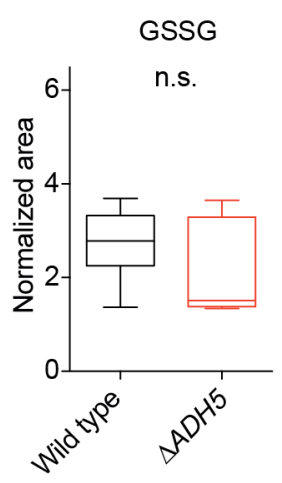

$$
\text { i }
$$

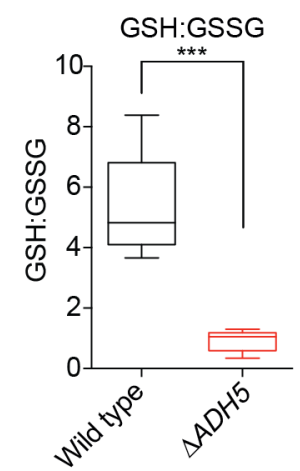

e

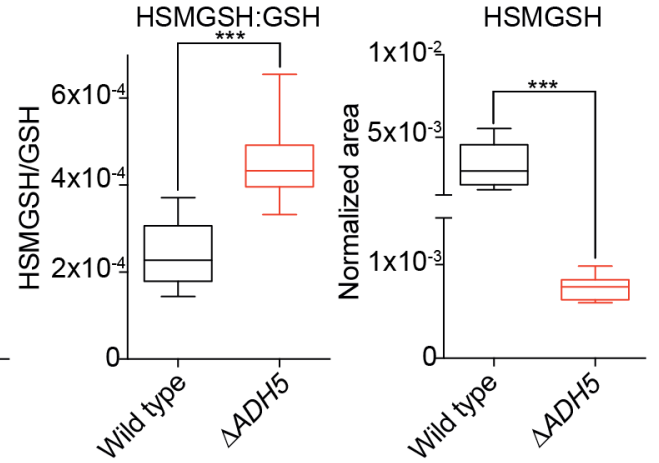

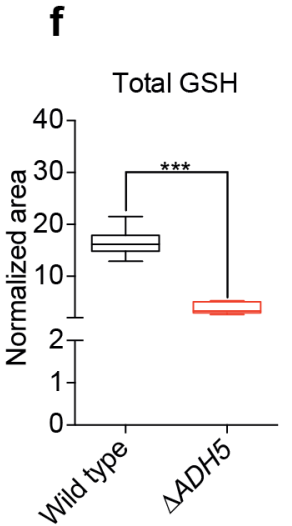

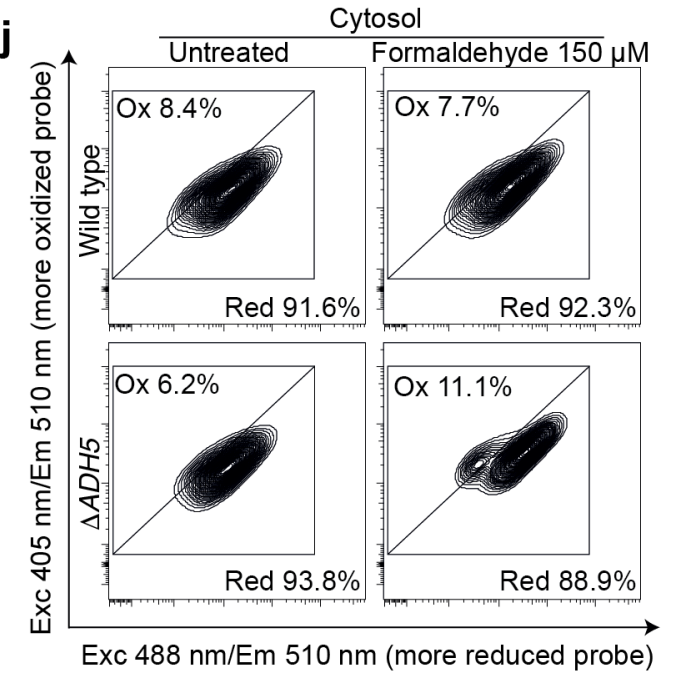

$\mathbf{k}$

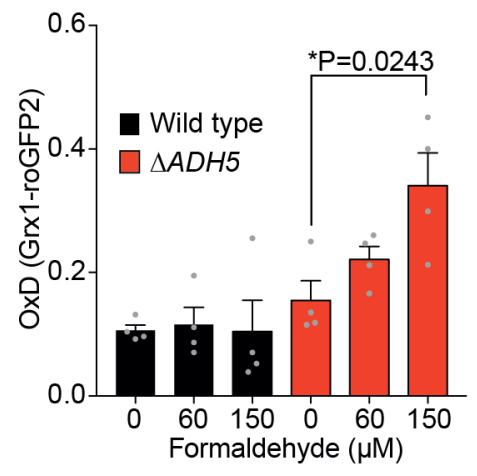




\section{Figure 6}

a

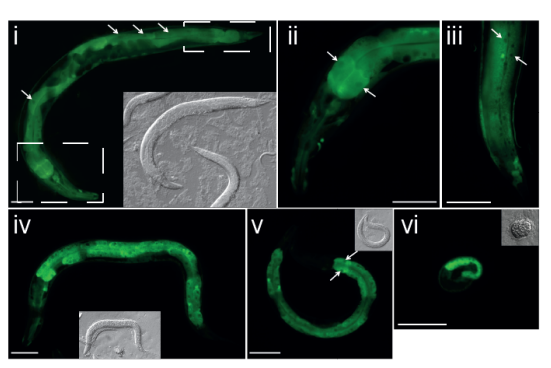

d

d $\quad \mathrm{N} 2 \quad \mathrm{~N} 2 \quad \mathrm{adh}-5 \quad \mathrm{adh}-5$

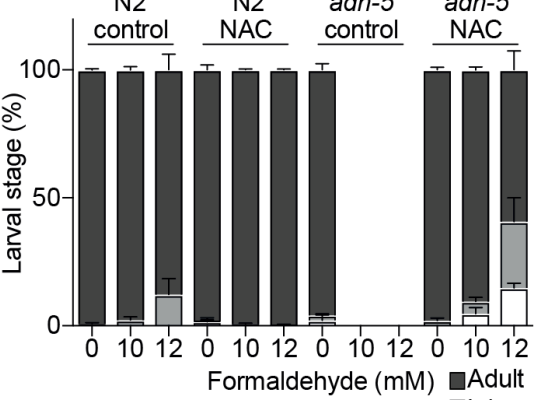
$\square$ L4

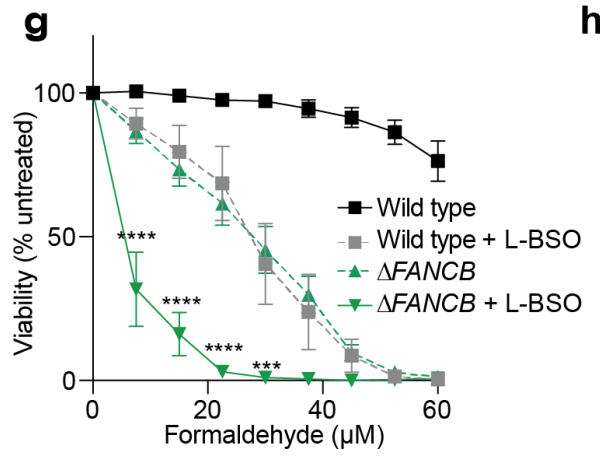

h b

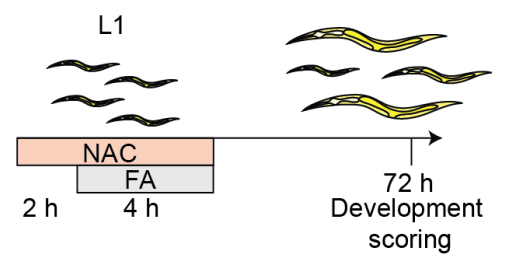

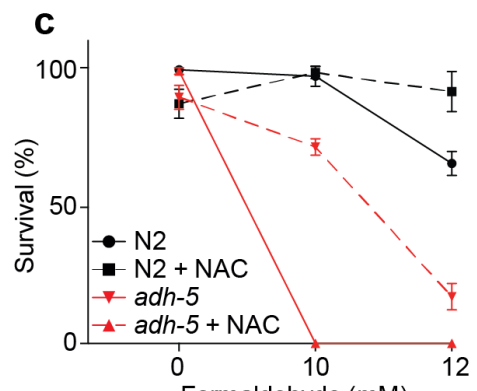

Formaldehyde (mM)

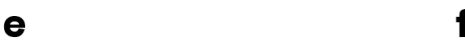

f $0 \mathrm{mMFA} 2 \mathrm{mMFA}$
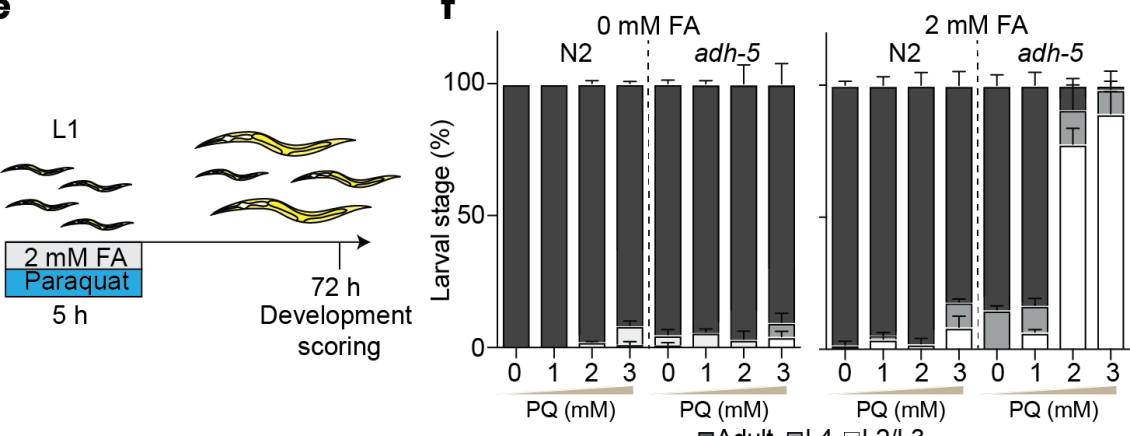

i

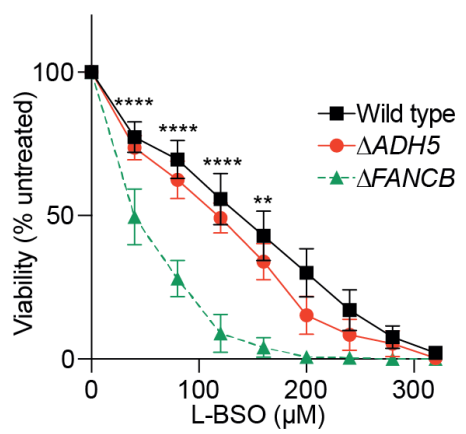

i Fanconi DNA repair DNA damage $\longleftarrow$ Formaldehyde

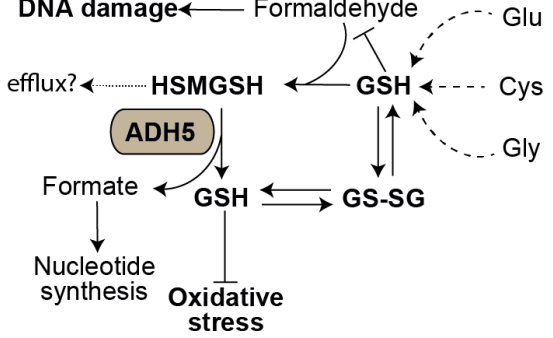




\section{Extended Data Fig. 1}

a

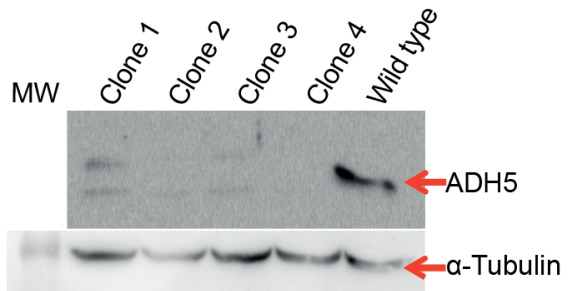

C

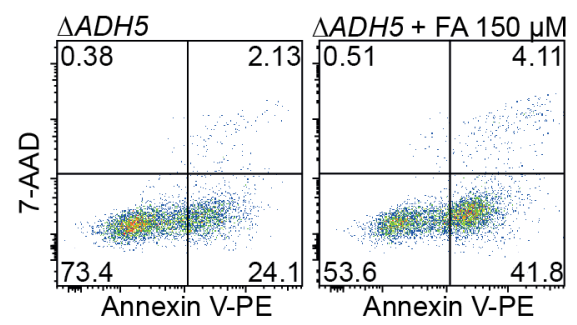

e

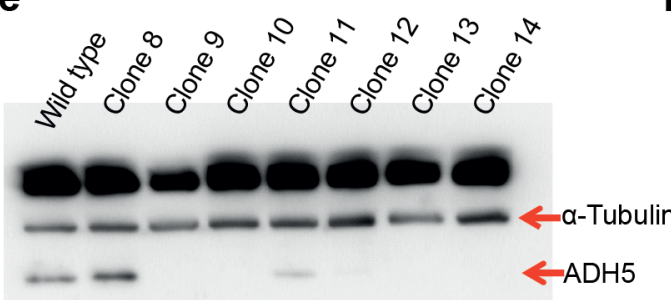

b

$\triangle A D H 5 c 4$

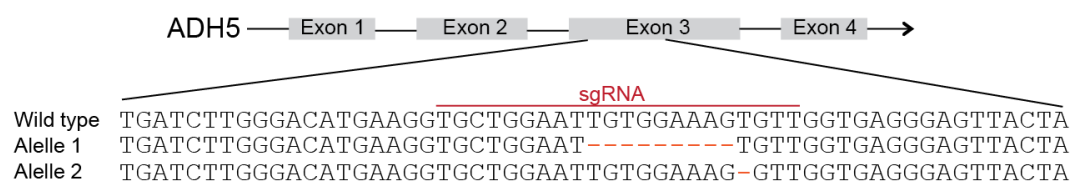

d

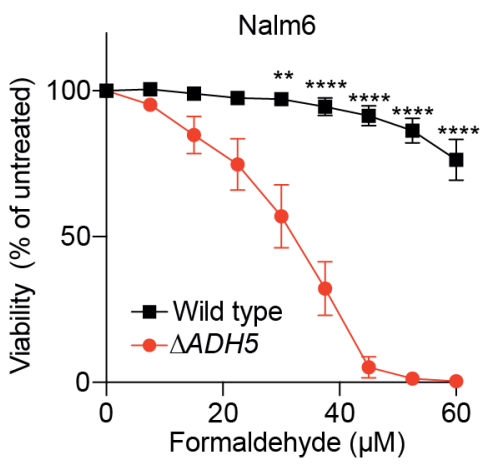

g

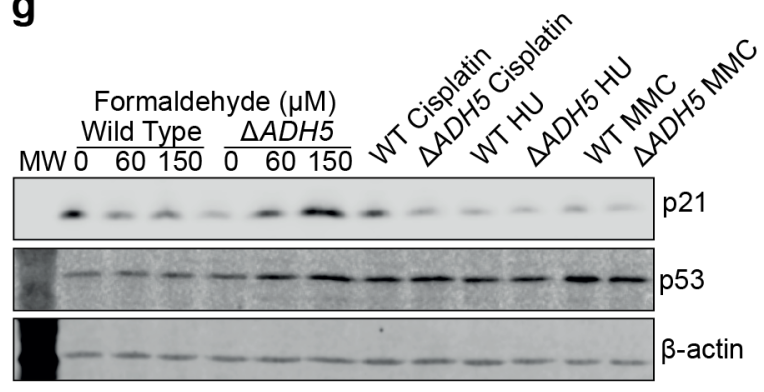

h
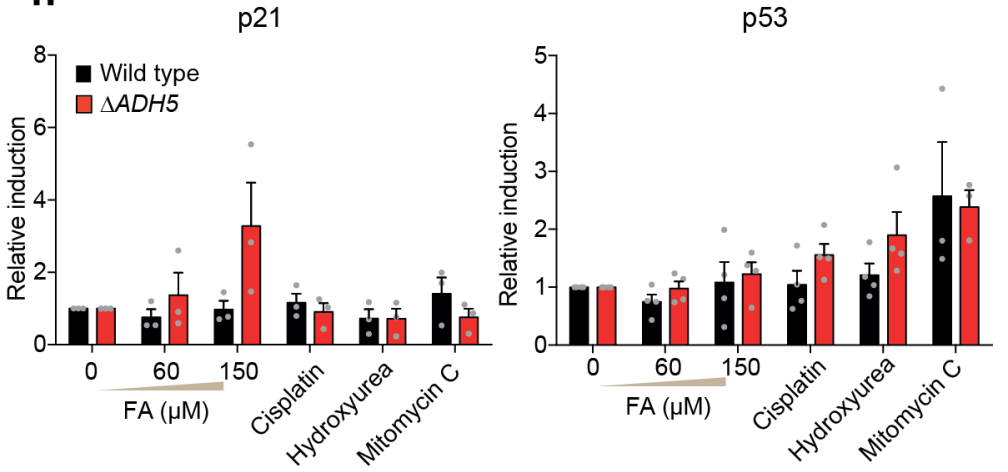

$\triangle P 53 \triangle A D H 5 c 14$

ADH5 - Exon 1 — Exon 2 Exon 3 - Exon $4 \longrightarrow$

sgRNA TGATCTTGGGACATGAAGGTGCTGGAATTGTGGAAAG-GTTGGTGAGGGAGTTACTA TGATCTTGGGACATGAAGGTGCTGGAATTGTGGAAA-TGTTGGTGAgGGAGTTACTA 


\section{Extended Data Fig. 2}

a

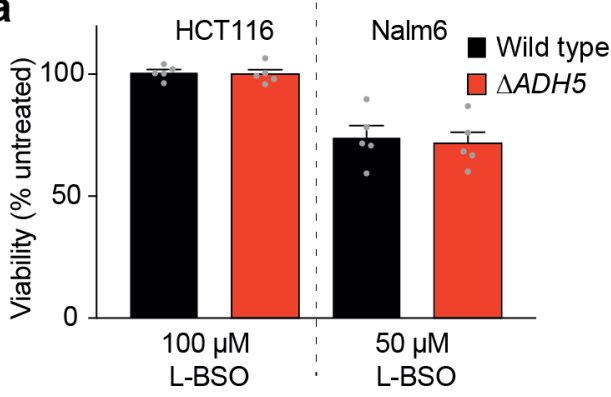

b

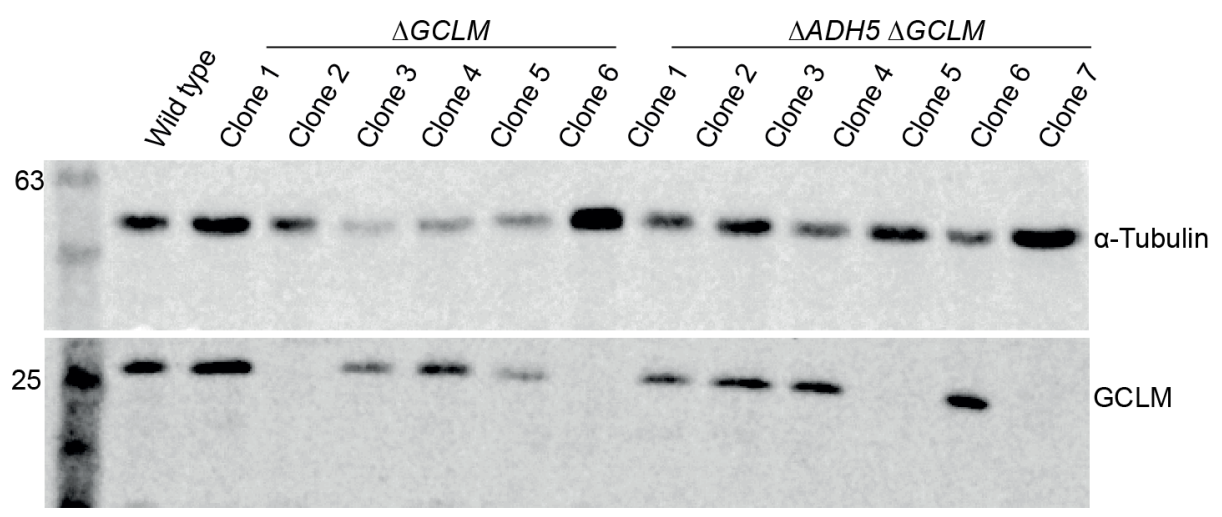

C

$\triangle A D H 5 \mathrm{c3}$

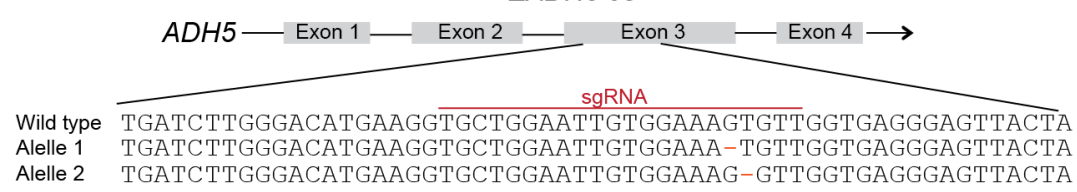

d
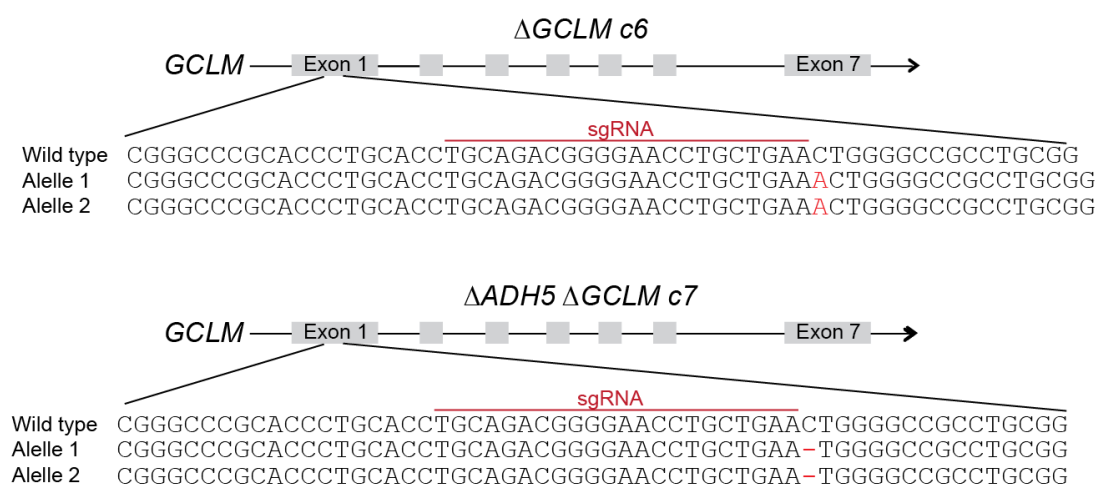


\section{Extended Data Fig. 3}

a

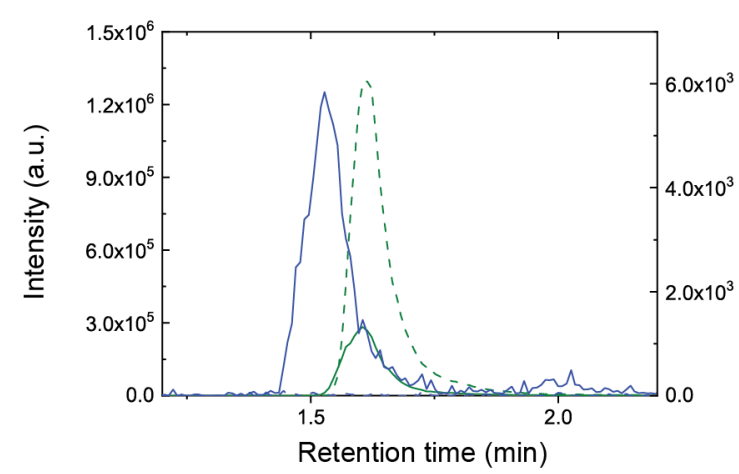

C

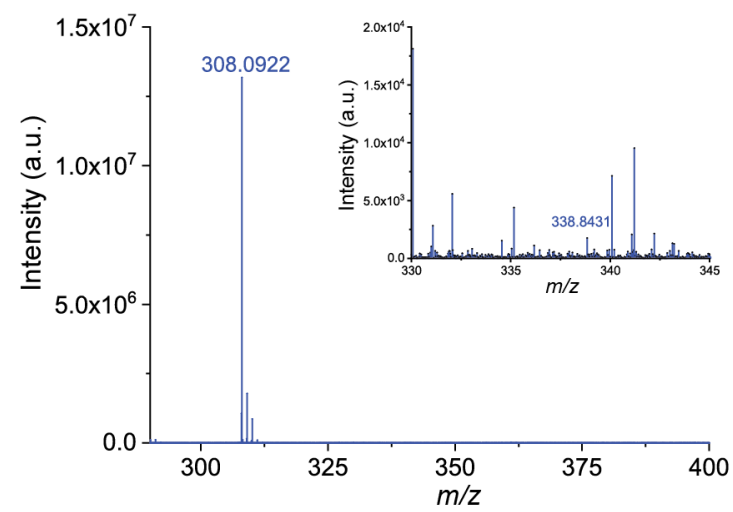

b

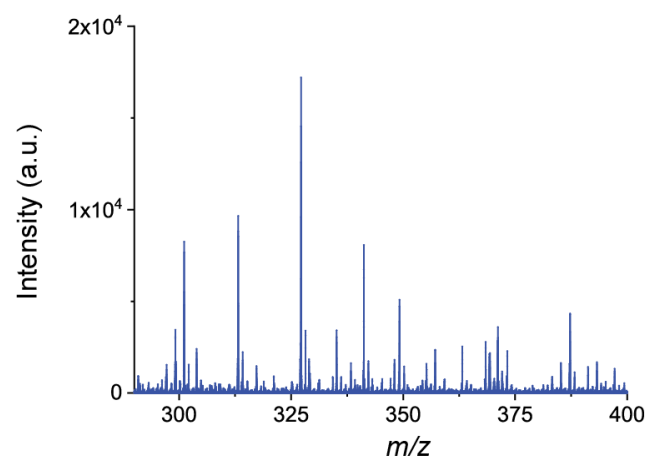

d

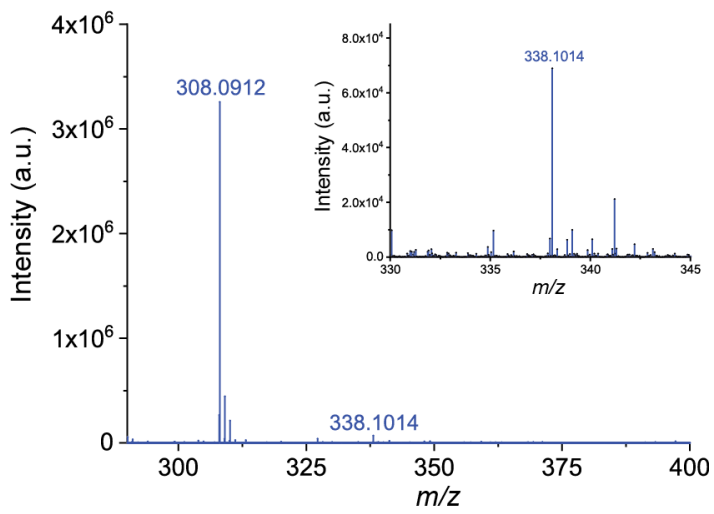




\section{Extended Data Fig. 4}

a

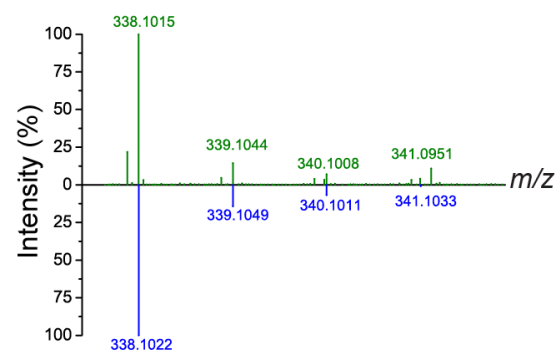

b

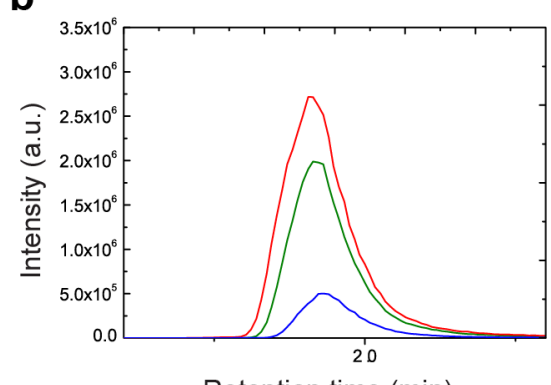

Retention time (min)

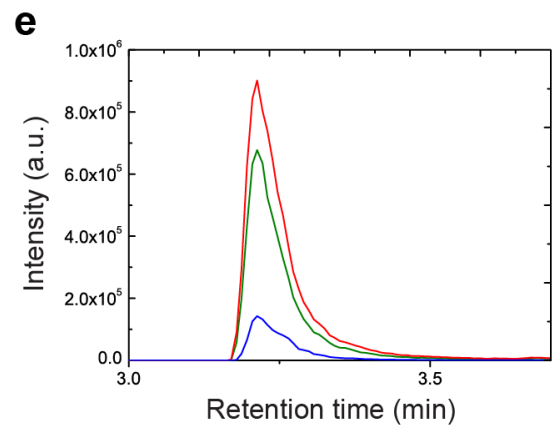

h

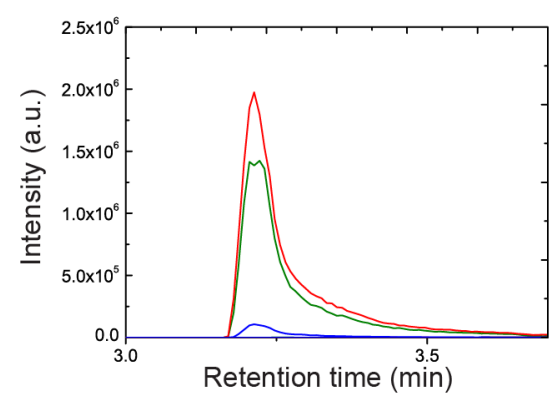

C

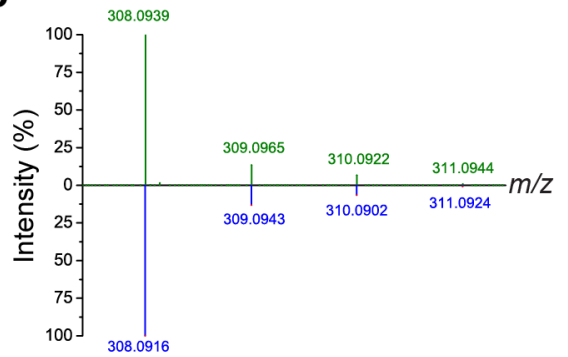

f

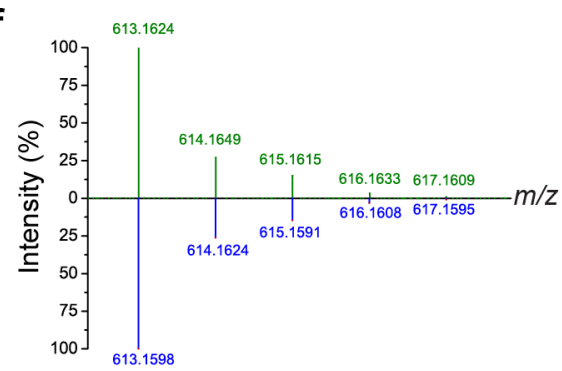

i

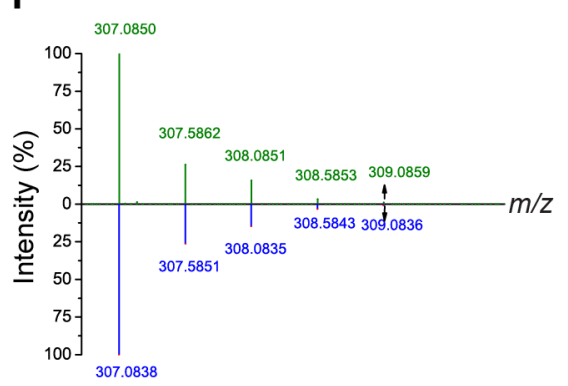

d
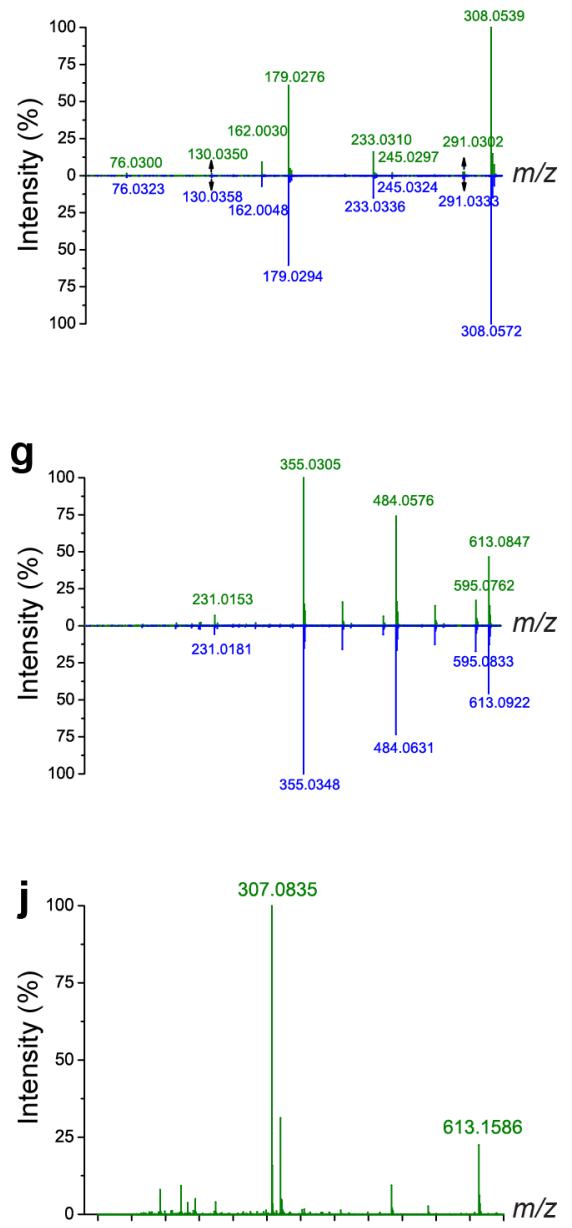


\section{Extended Data Fig. 5}

a

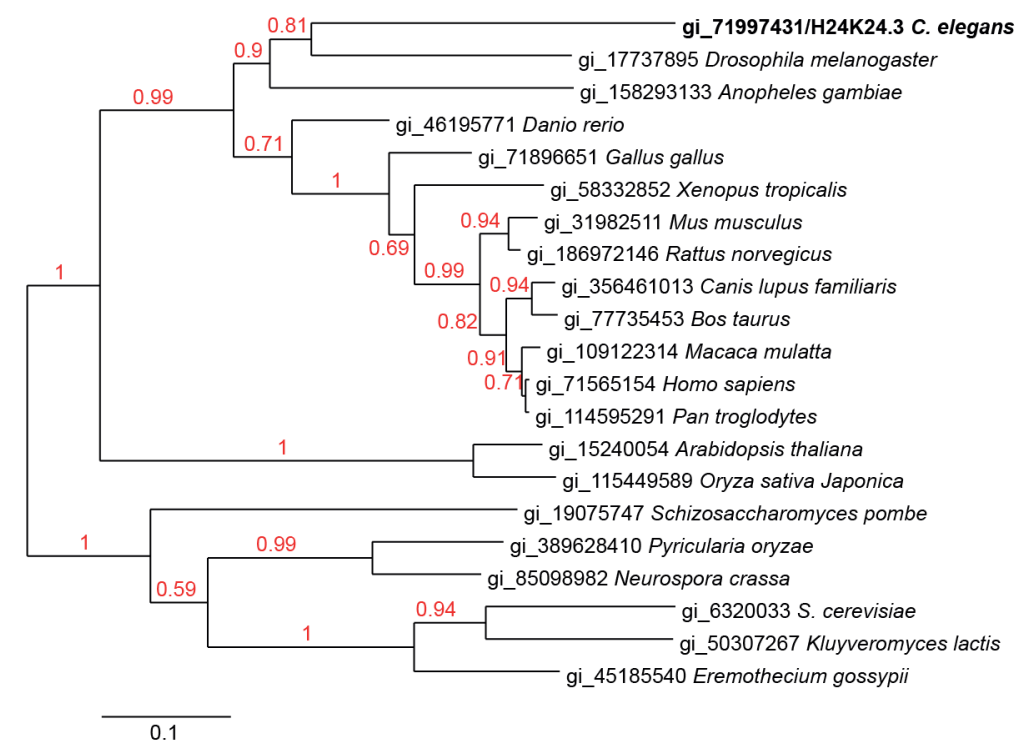

b
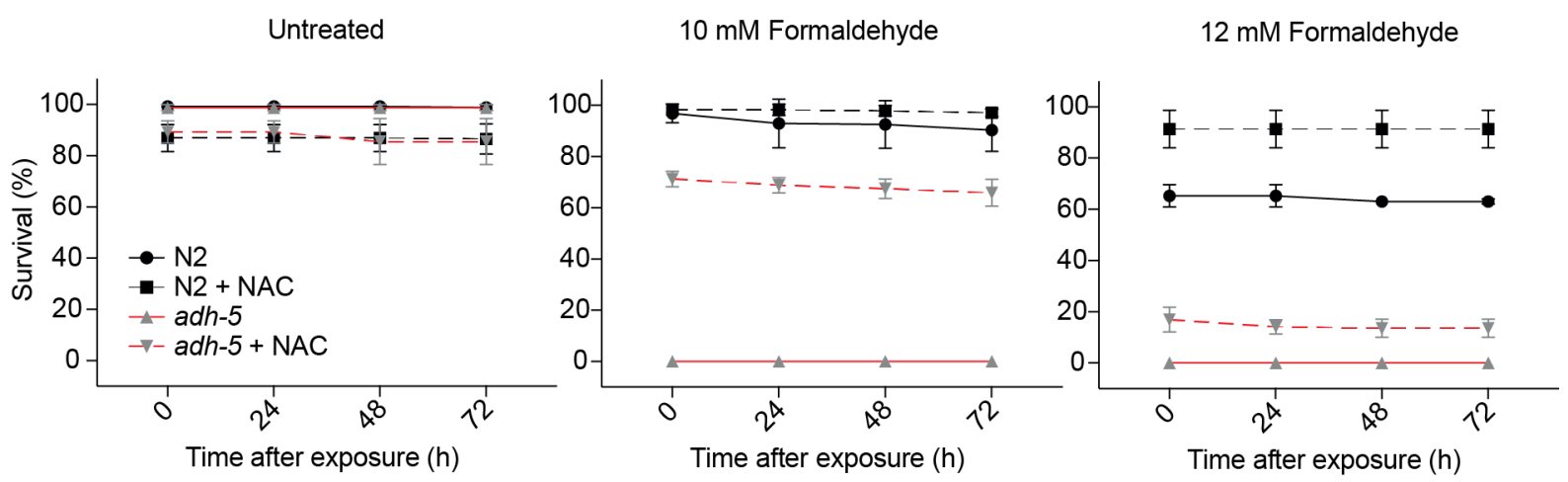

C

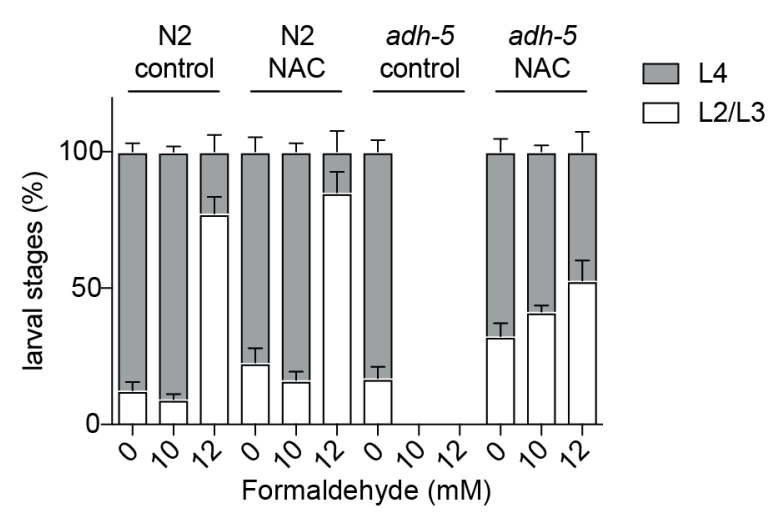


bioRxiv preprint doi: https://doi.org/10.1101/2020.05.14.090738; this version posted May 15, 2020. The copyright holder for this preprint (which was not certified by peer review) is the author/funder. All rights reserved. No reuse allowed without permission.

Source Data Fig. 2: Uncropped images Fig. 2

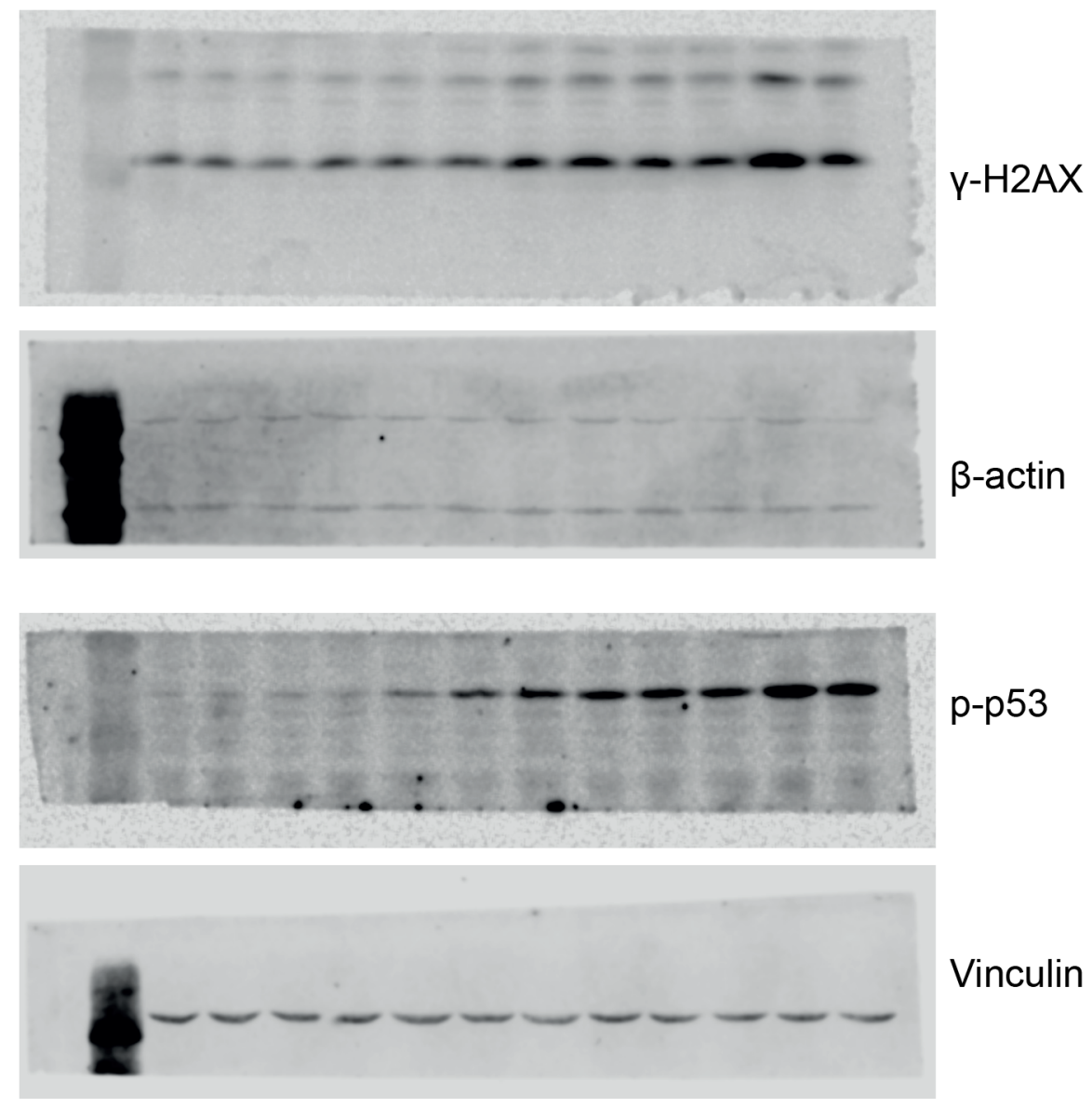


bioRxiv preprint doi: https://doi.org/10.1101/2020.05.14.090738; this version posted May 15, 2020. The copyright holder for this preprint (which was not certified by peer review) is the author/funder. All rights reserved. No reuse allowed without permission.

Source Data Extended Data Fig. 1: Uncropped images Extended Data Fig.1

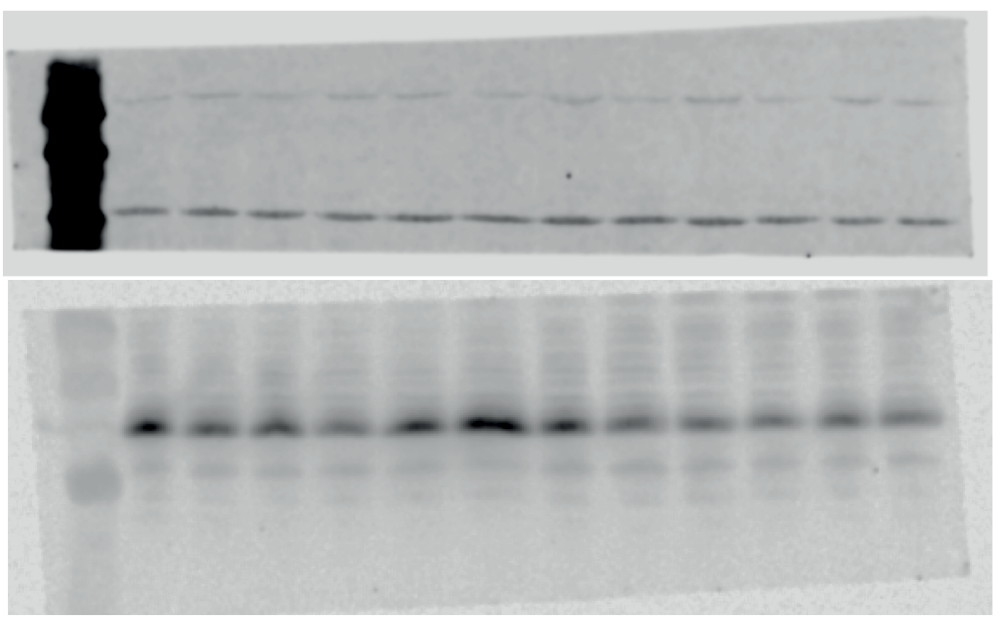

$\beta$-actin

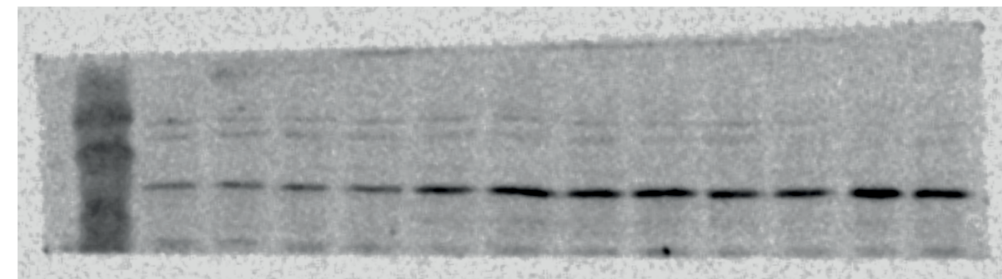

p53 


\section{Source Data Extended Data Fig. 5}

>gi|71565154 [Homo sapiens]

MANEVIKCKAAVAWEAGKPLS IEEIEVAPPKAHEVRIKIIATAVCHTDAYTLSGADPEGCFPVILGHEGA GIVESVGEGVTKLKAGDTVIPLYIPOCGECKFCLNPKTNLCOKIRVTOGKGLMPDGTSRFTCKGKTILHY MGTSTFSEYTVVADISVAKIDPLAPLDKVCLLGCGISTGYGAAVNTAKLEPGSVCAVFGLGGVGLAVIMG CKVAGASRI IGVDINKDKFARAKEFGATECINPODFSKPIOEVLIEMTDGGVDYSFECIGNVKVMRAALE ACHKGWGVSVVVGVAASGEEIATRPFQLVTGRTWKGTAFGGWKSVESVPKLVSEYMSKKIKVDEFVTHNL SFDEINKAFELMHSGKSIRTVVKI

>gi|114595291[Pan troglodytes]

MANEVIKCKAAVAWEAGKPLSIEEIEVAPPKAHEVRIKI IATAVCHTDAYTLSGADPEGCFPVILGHEGA GIVESVGEGVTKLKAGDTVIPLYIPQCGECKFCLNPKTNLCQKIRVTQGKGLMPDGTSRFTCKGKTILHY MGTSTF SEYTVVADISVAKIDPLAPLDKVCLLGCGISTGYGAAVNTAKVEPGSVCAVFGLGGVGLAVIMG CKVAGASRI IGVDINKDKFARAKEFGATECINPQDFSKPIQEVLIEMTDGGVDYSFECIGNVKVMRAALE ACHKGWGVSVVVGVAASGEEIATRPFQLVTGRTWKGTAFGGWKSVESVPKLVSEYMSKKIKVDEFVTHSL SFDEINKAFELMHSGKSIRTVVKI

>gi|109122314 [Macaca mulatta]

MANQVIKCKAAVAWEAGKPLSIEE IEVAPPKAHEVRIKIIATAVCHTDAYTLSGAEPEGCFPVILGHEGA GIVESVGEGVTKLKAGDTVIPLYIPOCGECKFCLNHKTNLCOKIRVTOGKGLMPDGTSRFTCKGKTILHY MGTSTF SEYTVVADISVAKIDPLAPLDKVCLLGCGISTGYGAAVNTAKVEPGSVCAVFGLGGVGLAVIMG CKVAGASRI I GVDINKDKFARAKEFGATECINPQDF SKPIQEVLIEMTDGGVDYSFECTGNVKVMRAALE ACHKGWGISVVVGIAASGEEIATRPFQLVTGRTWKGTAFGGWKSVESVPKLVSEYMSKKIKVDEFVTHNI SFDEINKAFELMHSGKSIRTVVKI

$>$ gi|356461013 [Canis lupus familiaris]

MANOVIKCKAAVAWEAGKPLS IEEVEVAPPKAHEVRIKI IATAVCHTDAYTLSGADPEGSFPVILGHEGA GIVESVGEGVTKLKAGDTVIPLYIPQCGECKFCLNPKTNLCQKIRVTQGKGLMPDGTSRFTCKGKTILHY MGTSTFSEYTVVADISVAKIDPLAPLDKVCLLGCGISTGYGAALNTAKVEPGSTCAVFGLGGVGLATIMG CKVAGASRI IGVDINKDKF SRAKEFGASEC INPODF SKP IOEVL IEMTDGGVDYSFECIGNVKVMRAALE ACHKGWGVSVIVGVAASGEEIATRPFQLVTGRVWKGTAFGGWKSVESVPKLVSEYMSRKIKVDEFVTHSL SFDQINEAFDLLHAGKSIRTVVKL

$>$ gi|77735453 [Bos taurus]

MANQVIKCKAAVAWEAGKPLS IEEVEVAPPKAHEVRIKI IATAVCHTDAYTLSGADPEGNYPVILGHEGA GIVESVGEGVTKLKAGDTVIPLYIPOCGECKFCLNPKTNLCOKIRVTOGKGLMPDGTSRFTCKGKTILHY MGTSTFSEYTVVADISVAKIDPLAPLDKVCLLGCGISTGYGAALNAAKVEPGSTCAVFGLGGVGLAVIMG CKMAGAARI IGVDINKDKFARAKEFGASECINPQDFSKP IQEVLIEMTDGGVDYSFECIGNVKVMRAALE ACHKGWGISVVVGVAASGEEIATRPFQLVTGRTWKGTAFGGWKSVESVPKLVSEYMSKKIKVDEFVTHSL PFDOINEAFDLMHAGKSIRTVVKL

$>$ gi|31982511[Mus musculus]

MANQVIRCKAAVAWEAGKPLS IEE IEVAPPKAHEVRIKILATAVCHTDAYTLSGADPEGCFPVILGHEGA GIVESVGEGVTKLKAGDTVIPLYIPOCGECKFCLNPKTNLCOKIRVTOGKGLMPDGTSRFTCKGKSVFHF MGTSTFSEYTVVADISVAKIDPSAPLDKVCLLGCGISTGYGAAVNTAKVEPGSTCAVFGLGGVGLAVIMG CKVAGASRI IGIDINKDKFAKAKEFGASECISPODFSKSIOEVLVEMTDGGVDYSFECIGNVKVMRSALE AAHKGWGVSVVVGVAASGEEISTRPFOLVTGRTWKGTAFGGWKSVESVPKLVSEYMSKKIKVDEFVTGNL SFDQINQAFDLMHSGDSIRTVLKM

>gi|186972146[Rattus norvegicus]

MANOVIRCKAAVAWEAGKPLS IEE IEVAPPOAHEVRIKI IATAVCHTDAYTLSGADPEGCFPVILGHEGA GIVESVGEGVTKLKAGDTVIPLYIPQCGECKFCLNPKTNLCQKIRVTQGKGLMPDGTSRFTCKGKPILHF MGTSTFSEYTVVADISVAKIDPSAPLDKVCLLGCGISTGYGAAVNTAKVEPGSTCAVFGLGGVGLAVIMG CKVAGASRI IGIDINKDKFAKAKEFGATECINPQDFSKS IQEVLIEMTDGGVDF SFECIGNVKVMRSALE AAHKGWGVSVVVGVAASGEEISTRPFQLVTGRTWKGTAFGGWKSVESVPKLVSEYMSKKIKVDEFVTGNL SFDQINKAFDLMHSGNSIRTVLKM

$>$ gi|71896651[Gallus gallus]

MASGVIKCKAAVAWEAGKPLSIEEVEVAPPKAHEVRIKIVATALCHTDAYTLSGADPEGCFPVILGHEGA GIVESVGEGVTKVKPGDTVIPLYIPOCGECKYCKNPKTNLCOKIRVTOGKGLMPDGTIRFTCKGKOIYHF MGTSTFSEYTVVADISVAKIDPAAPFDKVCLLGCGVSTGYGAAVNTAKVEPGSTCAVFGLGGVGLATVMG CKAAGASRI IGIDINKNTYAKAKEFGAAEC I SPQDFEKP IQEVLVEMTDGGVDYSFEC IGNVGVMRAALE ACHKGWGVSVIVGVAAAGQEISTRPFOLVTGRTWKGTAFGGWKSVDSVPKLVNDYMAKKIKVDEFVTHTL PFDKINEAFDLLHKGKSIRTVLKF

$>$ gi| 46195771 [Danio rerio]

MDTTGKVIKCKAAVAWEAGKPLSIEEVEVAPPKAHEVRVKIHATGVCHTDAYTLSGSDPEGLFPVILGHE GAGTVESVGEGVTKF KPGDTVIPLYVPQCGECKFCKNPKTNLCQKIRVTQGQGLMPDNTSRFTCKGKQLF HFMGTSTF SEYTVVAE ISLAKVDEHAPLDKVCLLGCGISTGYGAAINTAKVEAGSTCAVFGLGAVGLAVV MGCKSAGATRIIGIDVNPDKFEIAKKFGATEFVNPKDHSKPIOEVLVELTDGGVDYSFECIGNVGIMRAA LEACHKGWGTSVI IGVAGAGQEISTRPFQLVTGRTWKGTAFGGWKSVESVPKLVNDYMNKKLMVDEFVTH TLPFAQINEAFDLMHAGKSIRAVLQF

>gi|17737895 [Drosophila melanogaster]

MSATEGKVITCKAAVAWEAKKPLVIEDIEVAPPKAHEVRIKITATGVCHTDAFTLSGADPEGLFPVVLGH EGAGIVESVGEGVTNFKAGDHVIALYIPQCNECKFCKSGKTNLCQKIRLTQGAGVMPEGTSRLSCKGQQI FHFMGTSTFAEYTVVADISLTK INEKAPLEKVCLLGCGISTGYGAALNTAKVEAGSTCAVWGLGAVGLAV GLGCKKAGAGKIYGIDINPDKFELAKKFGFTDFVNPKDVADKGS IQNYLIDLTDGGFDYTFECIGNVNTM RSALEATHKGWGTSVVIGVAGAGQEISTRPFQLVVGRVWKGSAFGGWRSVSDVPKLVEDYLKKDLLVDEF ITHELPLSOINEAFDLMHKGESIRSIIKY

>gi|158293133 [Anopheles gambiae str. PEST]

LHPOVIKCKAAVAWEPKOPLS IETIEVAPPKAGEVRIKVTASGVCHTDAYTLGGLDSEGVFPVILGHEGA GVVESVGEGVTKFOPGDHVIPLYIPOCFECRFCKSPKTNLCPKIYHFMGTSTFAEYTVVAEVSLAKIDPS APLEKVCLLGCGIPTGYGAALNTAKVEPGSSCAIWGLGAVGLAVAMGCKAAGASRIIGVDINPAKFEIAK QFGCTEFVNPNDYKEPIQQVLVEKTDGGLDYTFECVGNVNTMRAALESCTRGWGVSVIVGVAEAGTEIST 
bioRxiv preprint doi: https://doi.org/10.1101/2020.05.14.090738; this version posted May 15, 2020. The copyright holder for this preprint (which was not certified by peer review) is the author/funder. All rights reserved. No reuse allowed without permission.

RPFQLVTGRTWKGTAFGGWKSVESVPKLVTSYLQKELKVDEFITHTMELEKINDAFTLMHEGKSIRSVVT L >gi|71997431[Caenorhabditis elegans]

MSSTAGQVINCKAAVAWSAKAPLSIETIQVAPPKAHEVRVKFQILYTAVCHTDAYTLDGHDPEGLFPVVL GHEGSGIVESVGEGVTGFAPGDHVVPLYVPOCKECEYCKNPKTNLCOKIRISOGNGFMPDGSSRFTCNGK OLFHFMGCSTFSEYTVVADISLCKVNPEAPLEKVSLLGCGISTGYGAVLNTCKVEEGSTVAVWGLGAVGL AVIMGAKAAGAKKIVGIDLIESKFESAKFFGATECINPKSVELPEGKSFQAWLVEQFDGGFDYTFECIGN VHTMROALEAAHKGWGVSCI IGVAGAGOEIATRPFOLVTGRTWKGTAFGGWKSVESVPRLVDDYMNKKLL IDEFITHRWNIDDINTAFDVLHKGESLRSVLAFEKI

>gi|6320033|ref|NP_010113.1|[ Saccharomyces cerevisiae S288C]

MSAATVGKPIKCIAAVAYDAKKPLSVEEITVDAPKAHEVRIKIEYTAVCHTDAYTLSGSDPEGLFPCVLG HEGAGIVESVGDDVITVKPGDHVIALYTAECGKCKFCTSGKTNLCGAVRATOGKGVMPDGTTRFHNAKGE DIYHFMGCSTFSEYTVVADVSVVAIDPKAPLDAACLLGCGVTTGFGAALKTANVQKGDTVAVFGCGTVGL SVIQGAKLRGASKIIAIDINNKKKOYCSOFGATDFVNPKEDLAKDQTIVEKLIEMTDGGLDFTFDCTGNT KIMRDALEACHKGWGOS I I IGVAAAGEE ISTRPFQLVTGRVWKGSAFGGIKGRSEMGGLIKDYQKGALKV EEFITHRRPFKEINQAFEDLHNGDCLRTVLKSDEIK

>gi|50307267|ref|XP 453612.1|[Kluyveromyces lactis]

MTSATAGKPIECVAAVAYEAGKPLTVEKI IVDAPKAHEVRVOVTHTAVCHTDAYTLSGVDPEGAFPSILG HEGAGIVESVGDGVTNVKVGDHVVLLYTAECGKCKFCKSNKTNLCGSVRATQGKGVMPDGTTRFHNLKGE PLLHFMGCSTFSOYTVVADVSLVTIDPSAPLSSVCLLGCGVTTGYGAAVKTANVQEGDTVAVFGAGTVGL SVVQGAKSRGASKIIVVDVNDQKKOWSMDFGATGFVNPLKDLKEGETIVSKLIDMTDGGLDFTFDCTGNV KVMRDALEACHKGWGQSI I IGVAAAGEE ISTRPFQLITGRVWKGSAFGGIKGRSEMGQLVTSYQKGDLKV DDFITHKRPFTE INNAFEDLHHGDCLRTVLDLAN

>gi|45185540|ref|NP_983256.1|[Eremothecium gossypii ATCC 10895]

MSETQGKPIOCTAAVAYAAGEPLRIEKVTVDPPKAHEVRIKIVNSAICHTDAYTLSGSDPEGLFPCILGH EGSGIVESVGEGVTNVKPGDHVVPLYTAECQOCKFCVSGKTNLCGAVRATQGKGVMPDGTSRFRNGKGET LYHFMGCSTFSEYTVVADVSVVAVDQQAPLETVCLLGCGVTTGYGAAVKTADVQEGDTVAVFGAGTVGLS VVQGAKARNASRI IVVDINDAKREWASKFGATDF INPKTDLKEGETIVARLIEMTDGGLDHTFDCTGNTK VMRDALEACHKGWGQS I I IGVAAAGQE ISTRPFQLVTGRVWKGSAFGGIKGRSEMGGLVRDYLNGTLKVQ EFVTHKRPFEEINSGFEDLHHGDCLRTVLSL

>gi|19075747|ref|NP_588247.1|[Schizosaccharomyces pombe]

MOOSPTAGK I INCKAAVAWOPAAPLS IENVOVFPPRVHEVRIKIVNSGVCHTDAYTLSGKDPEGLFPVIL GHEGAGIVESVGPQVTTVQVGDPVIALYTPECKTCKFCKSGKTNLCGRIRTTOGKGLMPDGTSRFSCNGN TLLHFMGCSTFSEYTVVADISVVAIERLAPLDSVCLLGCGITTGYGAATITADIKEGDSVAVFGLGSVGL AVIQGAVKKRAGRIFGIDVNPEKKNWAMSFGATDF INPNDLQSPIQDVLI HETDGGLDWTFDCTGNVHVM RSALEACHKGWGQS IVIGVAAAGQE ISTRPFQLVTGRVWRGCAFGGVKGRSOLPDLVKEYLDHKLEIDKY ITHRRPLKEINEAFTDMHNGNCIKTVLSIP

>gi|389628410|ref|XP 003711858.1|[Pyricularia oryzae 70-15]

MSTVGKTITCKAAVAWEAGKDLSIEDIEVAPPKAHEVRIEIYHTGVCHTDAYTLSGKDPEGAFPIVLGHE GAGIVESVGEGVTNVKVGDHVVALYTPECKECKFCKSGKTNLCGKIRATQGKGLMPDGTSRFKCKGKDLL HFMGTSTFSOFTVVADISVVAVOPEAPMDRTCLLGCGITTGYGAARVTANVEEGSSLAVFGAGCVGLSVV QGAVINKAGKI IVVDVNPAKEEWARKFGATDFVNPTKLPEGKTVVDALVELTDGGCDYTFDCTGNVQVMR AALEACHKGWGES I I I GVAAAGQE I STRPF QLVTGRVWKGCAFGG I KGRSQLPGLVDDYLQGRLKVDEF I THRKKLVEINNAFETMKQGDCIRAVVDMRAV

>gi|85098982|ref|XP_960697.1|[Neurospora crassa OR74A]

MASTVGKTITCKAAIAWGAGOELSYEDVEVAPPKAHEVRIQIKHTGVCHTDAYTLSGKDPEGAFPVILGH EGAGIVESVGEGVTNVKPGDHVIALYTPECKECKFCKSGKTNLCGKIRATQGRGVMPDGTSRFRARGQDI LHFMGTSTF SQYTVVADISVVAVNPEAPMDRTCLLGCGITTGYGAATITANVEKGSTVAIFGAGCVGLSV IQGAVANGASKI I AVDVNPSKEEWSRKFGATDFVNPSTLPEGQSVVDKLIELTDGGCDYTFDCTGNVKVM RAALEACHKGWGQSI I IGVAAAGQE ISTRPFMLVTGRVWRGSAFGGVKGRSOLPGLVEDYLNGKIKVDEL ITHRKKLAE INNAFEVMHOGDCVRAVVDMS

>gi|15240054|ref|NP 199207.1|[Arabidopsis thaliana]

MATOGOVITCKAAVAYEPNKTPLVIEDVOVAPPOAGEVRIKILYTALCHTDAYTWSGKDPEGLFPCILGHE AAGIVESVGEGVTEVQAGDHVIPCYQAECRECKFCKSGKTNLCGKVRSATGVGIMMNDRKSRFSVNGKPI YHFMGTSTF SOYTVVHDVSVAKIDPTAPLDKVCLLGCGVPTGLGAVWNTAKVEPGSNVAIFGLGTVGLAV AEGAKTAGASRI IGIDIDSKKYETAKKFGVNEFVNPKDHDKPIQEVIVDLTDGGVDYSFECIGNVSVMRA ALECCHKGWGTSVIVGVAASGQEISTRPFQLVTGRVWKGTAFGGFKSRTQVPWLVEKYMNKEIKVDEYIT HNLTLGEINKAFDLLHEGTCLRCVLDTSK

>gi|115449589|ref|NP_001048503.1|[Oryza sativa Japonica Group]

MASSTQGQVITCKAAVAWEANRRPMTIEDVQVAPPQAGEVRVKILFTALCHTDHYTWSGKDPEGLFPCILG HEAAGIVESVGEGVTEVQPGDHVIPCYQAECRECKFCKSGKTNLCGKVRAATGVGVMMNDRKSRFS INGK PIYHFMGTSTFSQYTVVHDVSVAKINPQAPLDKVCLLGCGVSTGLGAVWNTAKVEAGSIVAIFGLGTVGL AVAEGAKSAGASRIIGIDIDSKKFDVAKNFGVTEFVNPKDHDKPIQQVIVDLTDGGVDYSFECIGNVSVM RSALECCHKGWGTSVIVGVAASGQEISTRPFQLVTGRVWKGTAFGGFKSRSQVPWLVEKYLNKEIKVDEY VTHSMNLTDINKAFDLLHEGGCLRCVLATDK

>gi|58332852|ref|NP_001011502.1|[Xenopus tropicalis]

METAGKVVKCKAAVAWEAGKPLSIEEVEVAPPKAHEVRIKIVSTAVCHTDAYTLSGADPEGCFPVILGHE GAGIVESVGEGVTRVKPGDKVIPLYIPQCGECKFCLNPKTNLCQKIRITQGKGFMPDGSSRFTCKGQQIF HFMGTSTF SEYTVVADISVAKIDDSAPLDKVCLLGCGISTGYGAVINTAKVEPGSTCAVFGLGGVGLAVI MGCKVAGATRI IGIDLNKDKFVKATEFGATDCLNPADFKKPIODVLIEMTDGGVDYSFECIGNVGVMRAA LEACHKGWGTSVIVGVAASGQE IATRPFOLVTGRVWKGTAFGGWKSVDSVPKLVSEYMAKKIKVDEFVTH TLPFNSINEAFELMHAGKSIRGVLNY 